\title{
A Numerical Method for Studying the Circulation Patterns of a Fluid in a Cavity
}

by

Linda M. Stephani Thomas D. Butler 
Printed in the United States of America. Available trom National Techaical Information Service U S Department of Commerce 5285 Port Royal Road Springfield, VA 2215!

Price: Printed Copy $\$ 4.00$ Microtiche \$2.25 This report was prepared as an acrouml of work sponsored
bo tha. United Siates Government. Neither the Liniled States nor the linited States finerxy Research and Devplupn.ent Adminintrution. nor any to their employees, nor any oi their con warranty, express or implied. or assumes any lexul liahititv or responsibility for the aceuracy. completeness, or usefulness of anv informution. eppuratus, product. or process disclosed, or repretpnte that its uer would not infrime orivately owned
rixhts. 


\title{
A NUMERICAL METHOD FOR STUDYING THE CIRCULATION PATTERNS OF A FLUID IN A CAVITY
}

by

\author{
Linda M. Stephani and Thomas D. Butler
}

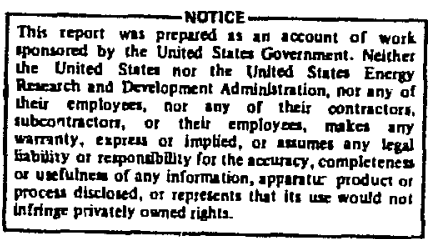

\begin{abstract}
This report describes a numerical method for studying the circulation patterns of a fluid in a cavity. The method incorporates three circulation-inducing mechanisms: (1) buoyancy induced by nonuniform initial distribution of heat throughout the fluid, (2) buovancy induced by removal of heat from the fluid, and (3) foreed convection induced by withdrawal of heated fluid and return of cooled fluid. A two-dimensional computer program, CIRCO, based on the Marker-and-Cell (MAC) technique, is used to study the circulation patterns. This report discusses the code and illustrates its capabilities by means of examples from studies conducted for the Pacer project, which investigates the concept of producing electrical power from energy released by thermonuclear explosions in a salt dome. Efficient engineering for withdrawing energy from the cavity requires an understanding of the circulation patterns of the heated fluid. CIRCO provides this information in the form of computer-generated plots.
\end{abstract}

\section{INTRODUC'TION}

CIRCO is a transient. two-dimensional, Eulerian fluid dynamics computer program that uses a modified form of the MAC ${ }^{1.2}$ solution technique. It is particularly applicable to study of buovancyinduced circulation patterns in incompressible fluid. The finite difference program solves the full NavierStolies equations coupled with a temperature transport equation in cylindrical coordinates with azimuthal s.vmmetry.

In CIRCO buoyancy circulation of a fluid can be initiated by:

- Nonuniform deposition of beat energy.

- Removal of heat from the working fluid through a heat exchanger.

- Forced convection induced by withdrawai of hasted fluid and return of cooled fluid.

The:e capabilities make CIRCO a useful research and engineering tool for a variety of applications, including post accident heat removal studies in nuclear reactor safety analysis and that reported here. study of circulation patterns in a spherical cavity for the Pacer project: :
Pacer is the name of a project designed to investigate the feasibility of economically generating electrical power from energy released by thermonuclear explosions. In this concept, a nuclear device is detonated in an underground cavity filled with a working fluid such as water or steam. Subsequently, the thermal energy from the explosion is extracted using heat exchangers and converted to electrical energy. The process is repeated periodically as the excess energy in the cavity is expended, thereby permitting continuous energy conversion.

To withdraw energy from the cavity efficiently. one must determine the ideal placement and pumping requirements of the heat exchangers. These can be determined with CIRCO by studying the circulation patterns of the working fluid using various heat exchanger configurations.

This report describes the CIRCO program. Included are brief descriptions of the technique (Sec. II) and the code (Sec. III), examples illustrating the code's capabilitie; (Sec. IV), and a listing of the program (Appendix). 


\section{THE TECHNIQUE}

\section{A. Equations}

Investigation of the dynamics of a circulating, incompressible fluid requires solution of the full fluid flow and heat transport equations. In cylindrical coordinates, assuming azimuthal symmetry and constant fluid density, the momenta and temperature transport equations are:

$$
\begin{aligned}
& \frac{\partial u}{\partial t}+\frac{1}{r} \frac{\partial r u^{2}}{\partial r}+\frac{\partial u v}{\partial z}=-\frac{\partial p}{\partial r}+v \frac{\partial}{\partial z}\left(\frac{\partial u}{\partial z}-\frac{\partial v}{\partial r}\right) . \\
& \frac{\partial v}{\partial t}+\frac{1}{r} \frac{\partial r u v}{\partial r}+\frac{\partial v^{2}}{\partial z} \\
& =-\frac{\partial p}{\partial z}-\frac{v}{r} \frac{\partial}{\partial r}\left[r\left(\frac{\partial u}{\partial z}-\frac{\partial v}{\partial r}\right)\right]-g_{z} B(T-\bar{T}) .
\end{aligned}
$$

and

$$
\frac{\partial T}{\partial t}+\frac{1}{r} \frac{\partial r T u}{\partial r}+\frac{\partial T V}{\partial z}=\frac{1}{r} \frac{\partial}{\partial r}\left(K r \frac{\partial T}{\partial r}\right)+\frac{\partial}{\partial z}\left(k \frac{\partial T}{\partial z}\right) .
$$

and the equation of continuity is

$$
\frac{1}{r} \frac{\partial r u}{\partial r}+\frac{\partial v}{\partial z}=0
$$

In these equations, $\mathrm{u}$ and $\mathrm{v}$ are the radial and axial velocities, respectively: $p$ is the rormalized pressure: $T$. the temperature; $u$, the kinematic viscosity coefticient: and $K$. the heat conduction coefficient. Buovancy effects are represented in Eq. (2) using the Brussinesq approximation. Here, $\mathrm{g}_{\mathrm{z}}$ is the gravity acceleration; $\beta$, the coefficient of thermal expansion: and $\bar{T}$, an average temperatur $c$ in each horizontal laver. $\overline{\mathrm{T}}$ is determined so that across any horizontal plane no net change of momentum results from buovancy effects.

$$
T(z) \equiv \frac{2}{R^{2}} \int_{0}^{R} T(r, z) r d r .
$$

where $R$ is the radial extent of the fluid regrion.

\section{B. Th: Solution Procedure}

In CIRCO, the governing differential equations are approximated by finite difference equations related to an Lulerian mesh of computing cells. The cells are rectangular in cross section and of uniform size with radial and axial dimensions $\delta \mathbf{r}$ and $\hat{b} \mathrm{z}$. respectively. Each is characterized by a position index (i,j) that designates the center of the cell and its relative position within the mesh. Associated with each cell are the quantities that specify the local average fluid properties. The defined locations of the velocity components, the pressure, and the temperature in cell $(i, j)$ are shown in Fig. 1. The velocities are located on cell boundaries, whereas the pressure and temperature are defined at the center. The relative position of each quantity within a cell is denoted by the subscripts.

To begin the calculation, initial values of the velocity, pressure, and temperature fields are specified for each cell. These are used 10 advance the solution one time step, ft. Thereafter. the process is repeated with the values of the dependent variahles: at a given time level, say $n$. used to obtain the solution at the new level, $n+1$. Thus. the solution proceeds in time.

The solution procedure through one time cycle is composed of three separate phases: the intermediate time level velocity calculation. the pressure-velocity iteration, and the temperature calculation.

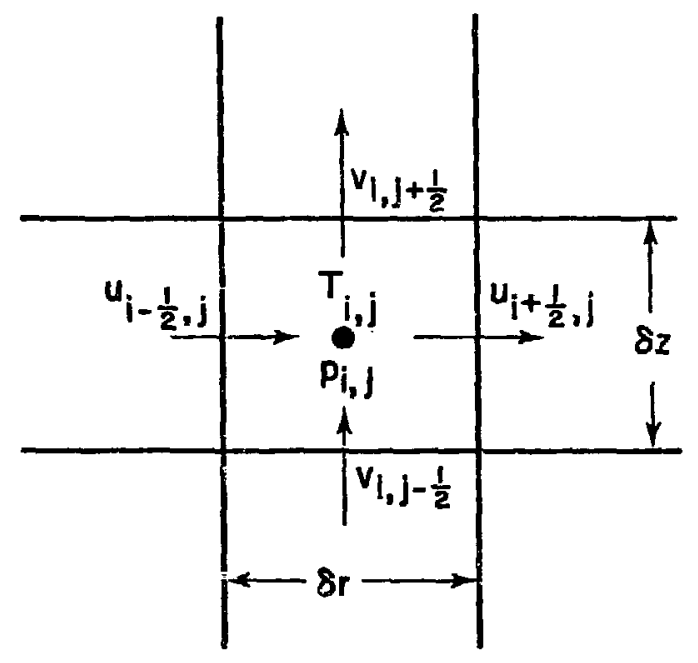

Fig. 1.

Location of the cell variables in a cell $(i, j)$.

1. Intermediate Time Level Velocity Calculation. In this phase, intermediate values of the velocity components are determined explicitly using 


$$
\begin{aligned}
& \tilde{u}_{i+j_{, j}, j}=u_{i+4, j}^{n}-\delta t\left\{\frac{1}{r_{i+l_{2}} \delta r}\left(r_{i+1} u_{i+3, j}^{n} u_{i+3 / 2, j}^{n}-r_{i} u_{i-4, j}^{n} u_{i+3, j}^{n}\right)\right.
\end{aligned}
$$

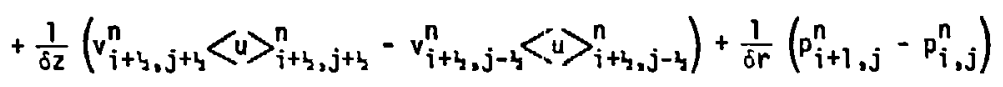

$$
\begin{aligned}
& \left.-v\left[\frac{1}{\delta z^{2}}\left(u_{i+4, j+1}^{n}-2 u_{i+z_{2}, j}^{n}+u_{i+h_{, j-1}}^{n}\right)-\frac{1}{\delta r \delta z}\left(v_{i+1, j+4}^{n}-v_{i, j+4}^{n}-v_{i+1, j-4}^{n}+v_{i, j-4}^{n}\right)\right]\right\} \text {. }
\end{aligned}
$$

and

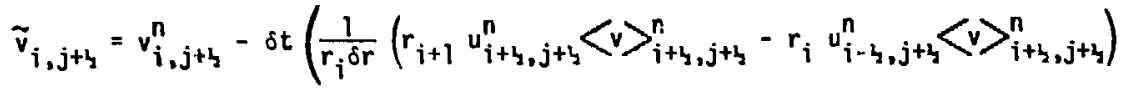

$$
\begin{aligned}
& +\frac{1}{\delta z}\left(v_{i, j+l_{2}}^{n} v_{i, j+3 / 2}^{n}-v_{i, j-\zeta}^{n} v_{i, j+\zeta}^{n}\right)+\frac{1}{\delta z}\left(p_{i, j+1}^{n}-p_{i, j}^{n}\right)+g_{2} B\left(\frac{T_{i, j+1}^{n}+T_{i, j}^{n}}{2}-\vec{T}_{j+\zeta}^{n}\right) \\
& +\frac{v}{r_{i}}\left\{\frac{1}{\delta r_{\delta} \delta}\left[r_{i+4}\left(u_{i+y_{, j+1}}^{n}-u_{i+y_{, j}}^{n}\right)-r_{i-\zeta}\left(u_{i-4, j+1}^{n}-u_{i-\zeta, j}^{n}\right)\right]\right. \\
& \left.\left.-\frac{1}{\delta r^{2}}\left[r_{i+4}\left(v_{i+1, j+l_{2}}^{n}-v_{i, j+h}^{n}\right)-r_{i-\zeta}\left(v_{i, j+4}^{n}-v_{i-1, j+\zeta}^{n}\right)\right]\right\}\right) \text {. }
\end{aligned}
$$

in which the tildes denote the intermediate level and the superscripts denote the time levels for the terms on the right-hand side.

A variable donor cell difference procedure is used in the cross-derivative transport terms; an example is

$$
v_{i+h, j+h}^{n}\langle u\rangle_{i+h, j+4}^{n}
$$

In this tarm. we define

$$
v_{i+h_{2}, j+4}^{n} \equiv \frac{1}{2}\left(v_{i+1, j+3}^{n}+v_{i, j+3}^{n}\right) \text {. }
$$

and

$$
\langle u\rangle_{i+\frac{1}{2}, j+\zeta}^{n}=\left(\xi_{v}+\frac{1}{2}\right) u_{i+h_{3}, j}^{n}-\left(\xi_{v}-\frac{1}{2}\right) u_{i+y_{,}, j+1} \text {. }
$$

where

$$
E_{v}=\alpha \operatorname{sign}\left(v_{i+y_{2}, j+y_{z}}^{n}\right)+\beta_{1}\left(\frac{\delta t}{\delta z}\right) v_{i+h_{2}, j+\zeta} .
$$

and $0 \leq a \leq 0.5$. The coefficient $\beta_{1}$ takes on a value of 0.5 when $\alpha=0$ if so-called "interpolated donor cell differencing" is desired: othierwise. $\beta_{1}$ is zero.

The definition of $\bar{T}_{j+1 / 2}^{n}$ in Eq. (6) is given by

$$
\bar{T}_{j+3}^{n} \equiv \frac{\sum_{i} r_{i}\left(T_{i, j}^{n}+T_{i, j+1}^{n}\right)}{2 \sum r_{i}} \text {, }
$$

where the indicated summation is over all pairs of cells for which each cell in the pair is a fluid cell.

2. Pressure and Velocity Iteration. The next phase of the cycle is implicit: in it time level $n+1$ values of pressure and velocity are determined. These are obtained so that the continuity equation is satisfied consistently with the boundary conditions for the problem. A complete description of the iteration process is given in Ref. 4 . Only' brief outline is sketched here to indicate the basic approach.

Generally, the velocities from Eqs. (5) and (6) do not satisfy the continuity equation. The finite difference approximation to it is

$$
\begin{aligned}
D_{i, j} & \equiv \frac{1}{r_{i} \delta r}\left(r_{i+l_{1}} u_{i+4, j}-r_{i-\frac{1}{2}} u_{i-4, j}\right) \\
& +\frac{1}{\delta z}\left(v_{i, j+l_{2}}-v_{i, j-\zeta}\right)=0
\end{aligned}
$$

in which the time levels are omitted. Upon substituting the tilde values into Eq. (8), we find

$$
\tilde{\mathrm{d}}_{\mathbf{i}, \mathrm{j}} \neq 0 \text {. }
$$

The desired velocity values are found by iterating the pressure field until the resulting velocities yield

$$
\left|0_{i, j}^{n+1}\right|<\varepsilon
$$


for each cel!. This is done by a point relaxaltion method in which the pressures and velocities are changed simultaneously. At each iteration level. the pressure is incremented by an amount

$$
p_{i, j}=p_{i, j}+\delta p_{i, j} \text {. }
$$

where

$$
\begin{aligned}
& \delta p_{i, j}=-\frac{\omega D_{i_{j}} \mathbf{j}}{\left(\frac{\partial U}{\partial p}\right)} . \\
& \left(\frac{\partial D}{\partial p}\right)=2 \delta t\left(\frac{1}{\delta r^{2}}+\frac{1}{\delta z^{2}}\right),
\end{aligned}
$$

and $\omega$ is an overrelaxation factor that has limits $0<$ $u^{*}<2$. Once the pressure is found, new velucities are deternined:

$$
\begin{aligned}
& u_{i+y_{, j}}=u_{i+y_{, j}}+\frac{\delta t}{\delta r} \delta p_{i, j} . \\
& u_{i-h, j}=u_{i-h, j}-\frac{\delta t}{\delta r} \delta p_{i, j}, \\
& v_{i, j+l_{2}}=v_{i, j+y_{3}}+\frac{\delta t}{\delta z} \delta p_{i, j} . \\
& v_{i, j-3}=v_{i, j-3}-\frac{\delta t}{\delta z} \delta r_{i, j} .
\end{aligned}
$$

This process is repeated intil Eq. (9) is satisfied to within a specified amoun', $\epsilon$, where $\epsilon$ is an acceptable error whose effects on the dynamics are negligible.

3. Temperature Calculation. With the final values of pressure and velocity determined for the cycle, the temperature transport equation is solved explicitly by in which the terms with coefficient $(1+\xi)$ on the right-hand side have been added to overcome the eflects of unfavorable truncation errors introduced by the difference approxination. "The value of $\xi$ is un input constant that varies between zero and unity. with zero corresponding to exact lowest order truncation error removal. and larger values sometimes specified to introduce numerical smonthing. The difference form for the convection terms is derived ising centered differences and the condition that the divergence of the velocity field must vanish.

\section{Boundary Conditions}

A number of different boundary conditions are permitted in CIRCO. These include conditions on both the velocity and temperature fields. Four kinds of velocity boundaries are delined:

- rigid, free-slip.

- rigid, no-slip.

- inflow.

- outflow.

Rigid boundaries are defined to coincide with cell boundaries. and the normal velocity component on the boundary vanishes. The tangential component has a vanishing gradient across a free-slip boundary and is zero at the wall in the no-slip case (see Fig. 2). Inflow and outflow boundaries also coincide with cell boundaries. and the normal velocit. components are specified values on these boundaries. The tangential component vanishes at inflow and outflow boundaries.

Two temperature condition options are available for rigid boundaries. Either the temperature is kept constant, or the wall is insulated so that there is no heat flo across the boundary. At inflow boundaries. the temperature is kept constant. whereas the outflow boundary is insulated.

$$
\begin{aligned}
& T_{i, j}^{n+1}=T_{i, j}^{n}-\delta t\left(\frac{1}{2 r_{i}^{j r}}\left(r_{i+3} T_{i+1, j}^{n} u_{i+3, j}^{n+1}-r_{i-b} i_{i-1, j}^{n} u_{i-l_{j}, j}^{n+1}\right)+\frac{1}{2 \delta z}\left(T_{i, j+1}^{n} v_{i, j+k}^{n+1}-T_{i, j-1}^{n} v_{i, j-b}^{n+1}\right)\right. \\
& -\left\{\frac{1}{2 r_{i} s r^{2}}\left[\left(k_{i+1, j}+k_{i, j}\right) r_{i+3}\left(T_{i+1, j}^{n}-T_{i, j}^{n}\right)-\left(k_{i, j}+k_{i-1, j}\right) r_{i-1,}\left(T_{i, j}^{n}-T_{i-1, j}^{n}\right)\right]\right. \\
& \left.+\frac{1}{2 \delta z^{2}}\left[\left(k_{i, j+1}+k_{i, j}\right)\left(T_{i, j+1}^{n}-T_{i, j}^{n}\right)-\left(k_{i, j}+k_{i, j-i}\right)\left(T_{i, j}^{n}-T_{i, j-1}^{n}\right)\right]\right\} \\
& -\frac{\delta t}{2}(1+\xi)\left\{\frac{1}{\delta r^{2}}\left[\left(u_{i+3, j}^{n+1}\right)^{2}\left(T_{i+1, j}^{n}-T_{i, j}^{n}\right)-\left(u_{i-j, j}^{n+i}\right)^{2}\left(T_{i, j}^{n}-T_{i-1, j}^{n}\right)\right]\right. \\
& \left.\left.+\frac{1}{\delta z^{2}}\left[\left(v_{i, j+3}^{n+1}\right)^{2}\left(r_{i, j+1}^{n}-T_{i, j}^{n}\right)-\left(v_{i, j-3}^{n+1}\right)^{2}\left(i_{i, j}^{n}-T_{i, j-1}^{n}\right)\right]\right\}\right) \text {, }
\end{aligned}
$$



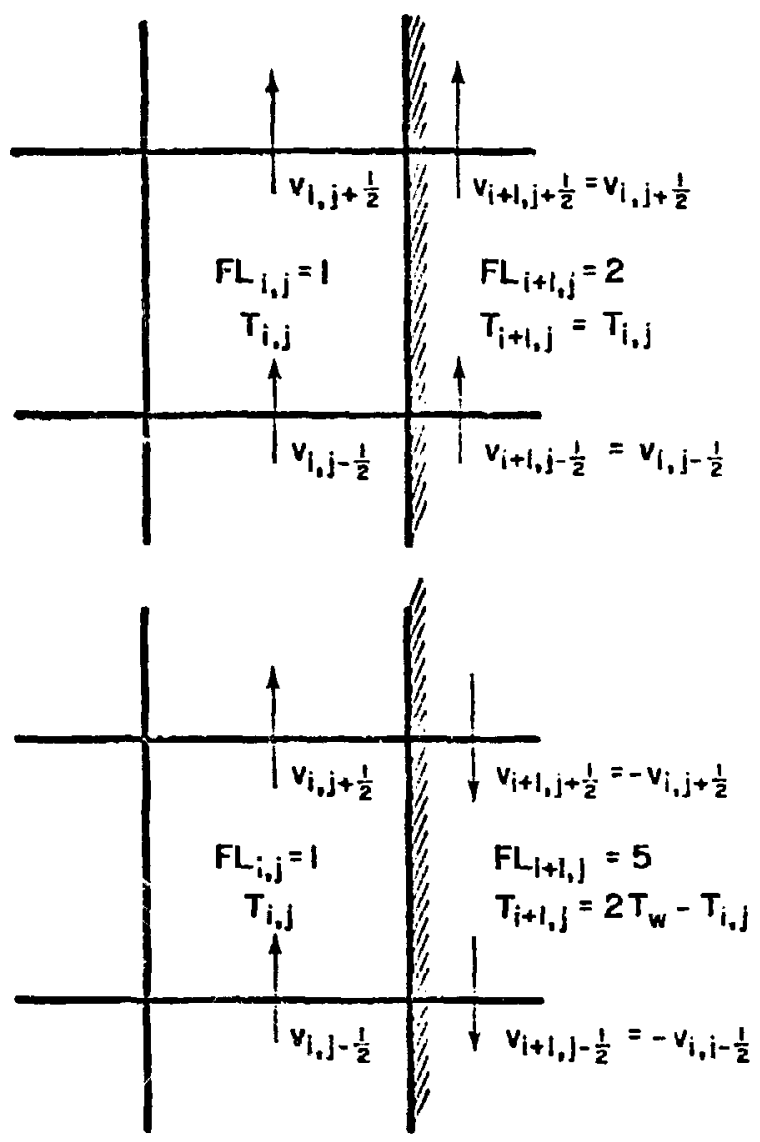

Fig. 2.

Boundars conditions applied to a rigid wall: (twp) a rigid, free-slip. insulated boundary und (bottom) a rigid. no-slip. constant temperature boundar:

To facilit ate the CIRCO logic, we surround the interior colls of the computation region with fictitious cells ssee fig. 4l. The hotudary conditions are applied by means of a cell-tlaguing scheme in which the computing and fictit ious cells are labeled with appropriate tlags to inclicate the cell type and the condition imposed. Thus. associnted with the computing mesh is an array of hags with the following definitions:

FI. $=1$ (interior thuid (edl).

FI. = 2 (rigidl, free-slip. insulated will or symmetry houndarsi.

Fl. $=3$ ( rigitl. no-slip, insulated wall .

Fl. $=\downarrow$ trigid. free-slip. const ant temperature wall!.

$\mathrm{Hl}=5$ (rigrid. no-slip. instant temperature wall.
$\mathrm{FL}=\mathbf{6}$ (inflow boundary)

$\mathrm{FL}=7$ (outflow boundary).

Computations are performed only for each cell with $F L=1$. Some of these fictitious cells may be within the interior region, when the flow region is not rectangular in cross section (see Fig. 5). As an example, consider the situation shown by Fig. 2 (topi in which a rigid, free-slip adiabatic bo'sndary is located on the right boundary of cell $(i, j)$ sc that $u_{i}+1 ;:=0$. The flag of cell $(i+1, j)$ is $F_{i+1, j}=2$. The $v$ components of velocity are specified so that $v_{i+1, j} \pm 1,2=v_{i, j} \pm 1 / 2$, and $T_{i+1, j}=T_{i, j}$. In Fig. 2 (bottom), the configuration is that of a rigid, no-slip, constant temperature wall on the right of cell $(i, j)$. In this case, $F L_{i+1, j}=5, v_{i+1, i} \neq 1 / 2=-v_{i, j} \pm 1 / 2$, and $T_{i+1 . i}=2 T_{w}-T_{i, j}$, where $T_{w}$ is the constant wall temperature. Similar expressions are found for the other possible combinations.

\section{Stability Conditions}

The criteria for numerical stability of the finite difference equations in CIRCO are the usual ones for the MAC method' with an additional criterion for the temperat ure equation. The time step for a given cell size is chosell so that:

$$
\begin{aligned}
& \frac{\left|u_{\max }\right| \delta t}{\delta r}<1 \text {. } \\
& \frac{L^{v} \max \mid \delta t}{\delta 2}<1 \\
& v \delta t<r \\
& v>\max \left[\left(\frac{\delta t}{2} u^{2}+\frac{\delta r^{2}}{2} \frac{1}{r} \frac{\partial u r}{\partial r}\right),\left(\frac{\delta t}{2} v^{2}+\frac{\delta z^{2}}{2} \frac{\partial v}{\partial z}\right)\right] . \\
& {\left[r+1 / 2(1+\xi)\left(u^{2}+v^{2}\right) \delta t\right]_{\max } \delta t<\tau .}
\end{aligned}
$$

Here, the subscript. max. indicates the largest values of the indicated quantities in the computing mosh. I' is given by

$$
r=\frac{\delta r^{2} \delta z^{2}}{2\left(\delta r^{2}+\delta z^{2}\right)} \text {. }
$$

(IIRCO has an automatic built-in time step control that has proved useful for application to cavity circulation problems. The time step is automatically increased by a factor TFAC'T. provided 


$$
\frac{2 \delta \pm V_{\max }}{(\delta r+\delta z)}<0.15
$$

where $V_{\text {max }}$ is the highest velocity in the computing mesh. Conversels. the time step is atumatically decreased by a tactor $\left(\mathrm{TFACT}^{-1}\right.$. provided

$$
\frac{2 \delta t v_{\max }}{(s r+\delta z)}>0.7 \text {. }
$$

The quantity. TFACT, is an input number in the code, and it is typieally chosen to equal 2.11.

\section{THE CODE}

There are two major sections of CIRC? the setup, or initializat ion. section and the calculat ional section. Figure 3 shows the code layout. In the in. itializalion section. requirements for a particular problen are defined. including the information needed is specify the initial and houndary conlditions. and whether the problem is to use informalion stored on magnetic tape or data from cords. Afier these quantities are determined. cont rol transiers to the calculational section where it remains for the duration of the computation. The primary cell quant it ies. u. $v$. p. and T are calculated by the procedure described in Siec. II. The rest of this section amplifies on the initializas ion section and describes the computing mesh. input data. output options. and mannetic tape restart capabilities.

\section{A. The Initialization Section}

Requirements for the flow problem in be calculated are specified in the init ialization section. The basic steps and decision points within the cocle are summarized in Fig. 3. The numbers in elongated ovals are FORTRAN statement numbers within the code.

CIRCO begins by reading two input cards. the tirst containing the problem identification and the second includiny data that cletermine the initialization procedure. When a calculation is starting from initial data, the control proceeds to region 1(15). where other duta cards are read, problem constants are computed. and initial quant ities for the computing cells are set. Control is then transferred to the calculational section. which begins at region 1000). If. however. the problem is to be restarted from data stored on magnetic tape, the code branches to region i50). where the tape is read. One can then change the tape information by reading additional data cards and calculating new problem constants. If such changes are desired, cont rol returns to region 105. where the appropriate quantities are determined, and then advances to lengion :3499. When 110 changes are necessialy, rontrol proceeds directly 11 region :3499.

\section{B. The Computing Mesh}

Figure of diagrams the basic ('IRC'() (omputing mesh. Indicated are the fluid region (I $\times$, I colls) and the fiet sitous cells (shaded region) surrounding it. The symmetry axis is one cell in frum the left buun. dary of the mesh. The thuid region courclinate's ance indicit ed oun the interior mesh comers where li: $=1 \times$

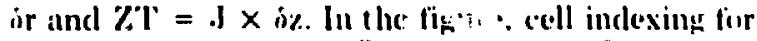
the mesh reguires $I M=\mathbb{I}+2$ and $' M=. j+2$. Thihasice mesh of rect angular crosis sect ton is specified in the input dat a ly setting $S C X=11.01$ see Sec. lil.(\%).

To represent a spherical cavity with the ('IlRC'() cumputing mesh. the eurved limundaries of tho cowity are approximated hy straight line segments coincident with cell butud aries, as Fign. is incliontes. Here the shaded region rapresents the nontluid portion. This option is specified by setting $S(X)=1.11$ in the inpul data. The cavity radius is R:2. and $Z \mathrm{~T}=2.11 \mathrm{~K} \cdot 2)$.

Also shown in Fig. is is an optional spherical hented port ion isee Sec. Ill-( ) an the fluid whose circular cross section is similarly approximated hy. st raight line sezments coinciding swith cell boun. daries.s. The region of radial dimension $R I$ is centered at height $\% 1$ above the cavity hottum. This represents a region whose temperalture differs irom that of the surrounding thid in the cavity at ititiati time. When $S(X)=0.0$, the heated portion is rec. langular in cross section with radial dimonsions R I and it extends a length. ZI/2.1). above and below the axial location 71 .

The cavity boundary conditions are applied. ace(ording to the preseriptions of Sec. II-C in I wo steps. First. the cells bounding the fluid region on the top. right. and bottom are thagged appropriately for the velocity and temperature conditions specified for the avity walls. Further, the cells along the symmetry axis. the left boundary of the fluid region, are flagged as rigicl. free-slip. insulated boundary cells. Second. segments of the cavity wall may require clifferent velocity and temperature conditions in reflect the presence of inflow and outflow ports or cooling plates. This alteration is accomplished by using an optional set of input data which identifies the particular segment and the appropriate conditions (see Sec. III-C). 
Initialization Phase

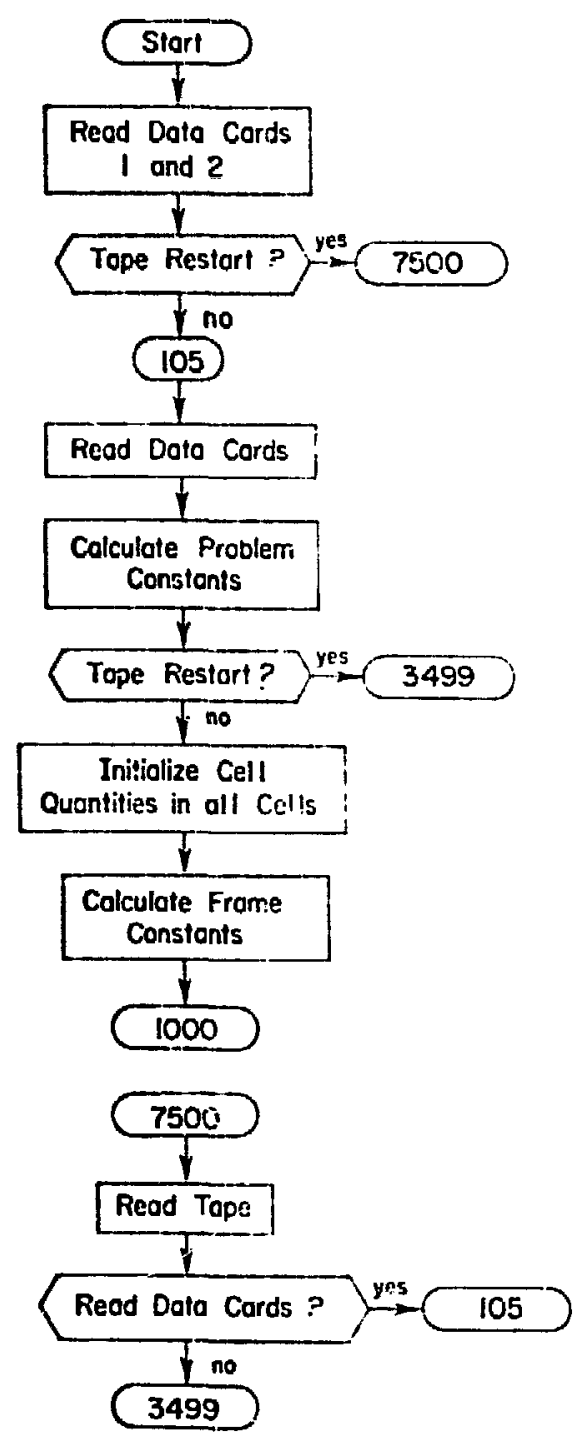

Calculational Phase

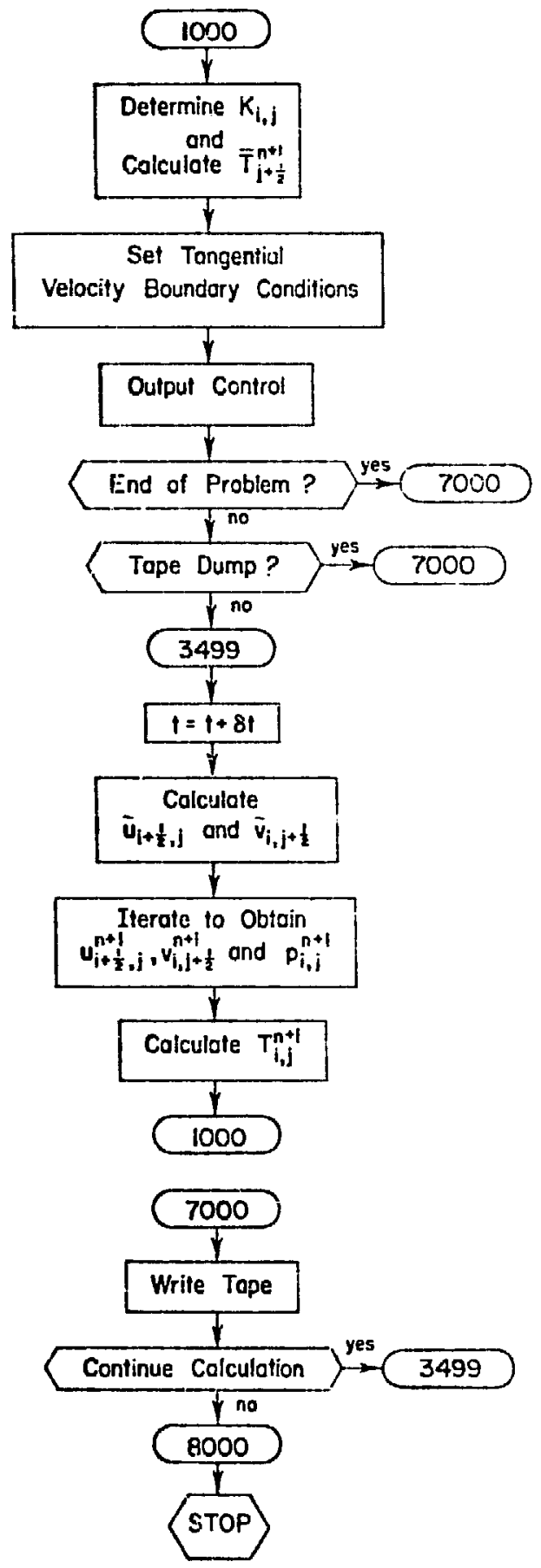

Fig. 3.

CIRCO flou diagram. 


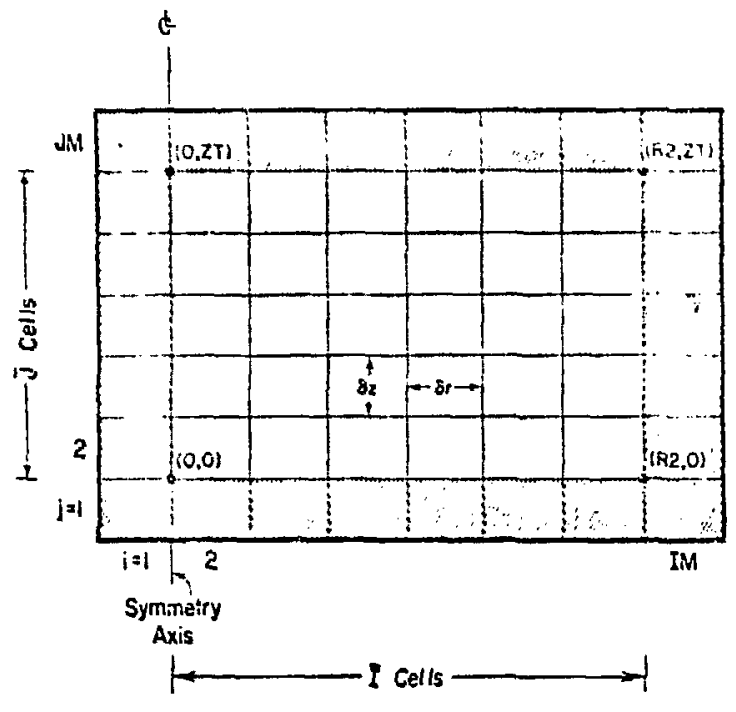

Fig. 4.

The CIRCO mesh shouing a fluid region of rectangular cross section.

\section{The Input Data}

CIRCO's input card deck may consist of three categories of data. The first delines the source of the initializing information: the second, the general problem requirements: and the third. the special problem requirements. In this section we list the dat a cards. their FORTRAN format statements, and the quantities they contain.

\section{Card Na. 1 (Format: 10AX).}

Columns $2-80$ are used for the problem identification for prints and plots. To allow for carriage control, column 1 is left blank. This card is required for each problem.

\section{Card No. 2 (Format: 3(6x, F12.5)).}

This card contains the quantities that determine the source of the initializing information. It must be included for each problem.

TD1 = the source identifier, where:

$0.0=$ a magnetic tape.

$1.0=$ data cards.

TD. $=$ the tape dump number.

TD: $3=$ the flag that determines the procedure after a tape is processed, where:

$0.0=$ do not read data cards,

$1.0=$ read data cards.

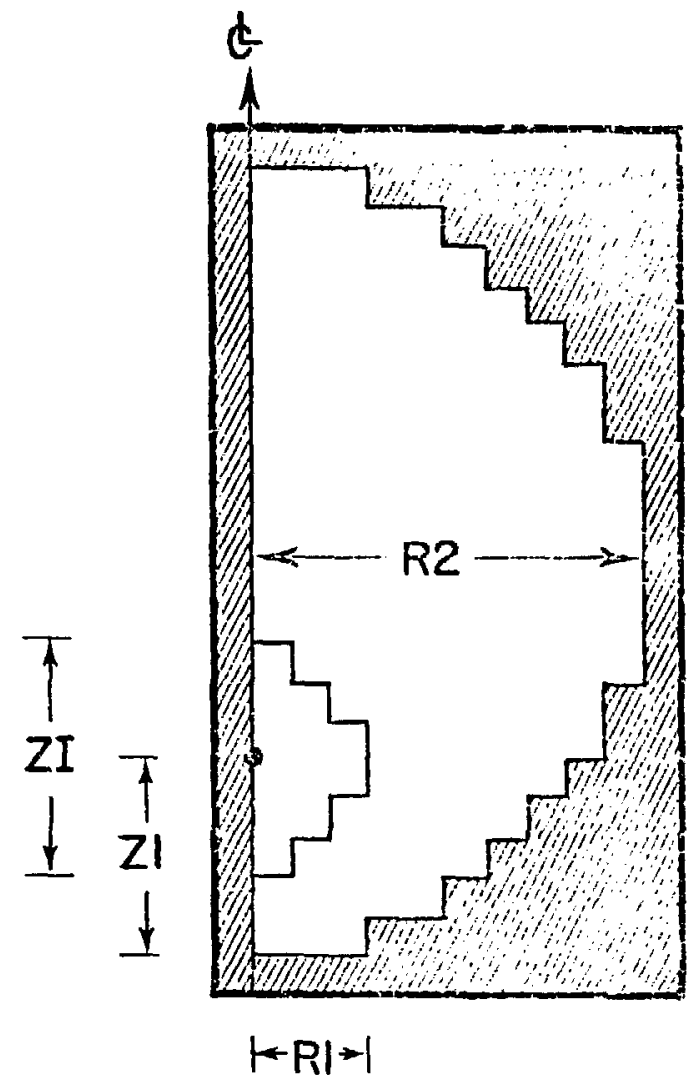

Fig. .5.

The mesh approximating a circular cavity. An optional heuted part of the fluid appears in the bottom half of the mesh.

Card No. 3 (Format: 10A8).

This card contains the same information as ('ard 1. hut it is included only when $\mathrm{TD} !=0.0$. Otherwise. it is omitted from the input deck.

The quantities on Cards 4 through 14 define the general problem requirements, such as cell dimensions. initial lluid properties, houndary information. sutput specifications, and time-related quantities. These dat a are necessary if the calculation begins at a time of zero or if new data are required for problems restarted from magnetic tape. The floating point data on Cards 4 through 12 are stored in the XPIT array: the integer data on Cards 13 and 14 are stored in the NPUT array.

Card No. 4 (Format: 6x, 12, 10x, 3(6x, F12.5))

NUM $=$ the number of floating point quantities stored in the XPUT array.

$\mathrm{DR}=\delta \mathrm{r}$, the cell dimension in the $\mathrm{r}$ direction.

$\mathrm{DZ}=\delta z$, the cell dimension in the $z$ direction.

DT $=\delta$, the initial value of the time increment. 
Card No. 5 (Format: $1($ (fx, Fle.j))

$R I=$ the radial dimension of the uptional inberiur heitled resing idefault vilue $=0.01$.

$\% !=$ the center perition in the $z$-dircertion of the optional interis heated region measured from

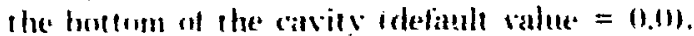

$7.1=$ the axial length of the optional interior heited region !defiult value $=0.01$. With a spherieal

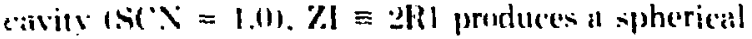
interior heated regient. For a nompphericial calvity

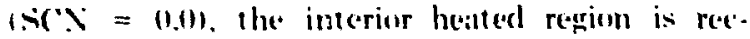
tangular in crass section and of estent $R 1 \times 7$.

$R:=$ the radial dimension of the computing mens.

Card No. li (format: 4(tix, Fle.si))

IT = the intial temperature of the optiomal interior heated region tdefault value $=11.011$.

$Y==$ the initial temuerature of the lluiri cells.

Twi. = the temperat ure of the rigid bundary. TIIt is zorn for an insulated wall and a specified value tor a consiant temperallure wall.

IIX $=$ the initial radiat componemt of velucity firr the thid cetls.

Card No. $i$ (Format: t(fix. Fl2.ĩ))

VIX $=$ the initial $\%$ component of velecity for the fluid a sills.

IJX = the intial pressure in the fluid eells.

$(1)=K$. the heat conduction conticient.

$\mathrm{VH}$. = the carity wall velocity hundary condition flag. where:

$$
\begin{aligned}
& 0.11=\text { a tree-slị boundary. } \\
& 1.11=\text { a no-silip boundary. }
\end{aligned}
$$

Gird No. 8 (Format: f(fix, Fl2.ĩ))

TFM = the cavity wall te:nperature boundary condition flay. where:

$$
\begin{aligned}
& 0.1)=\text { an insulated boundary. } \\
& 1.0=a \text { constant temperatore boun- }
\end{aligned}
$$

dary.

CPI. = the constant temperature plate flag. where:

$$
0.0=\text { no plate. }
$$

$1.0=$ at last one plate included tre-

quires the "constant temperature plate data package." described in sec. III.C.11.

PIRTI = the inflow port flag. where:

$0.0=$ no port

$1.0=$ at least one port included (requires the "intlow port data package." described in Sec. III-C.2).
PRTO = the outllow port thag. where: $0.0=$ no port.

$1,0)=$ at least one port included 1 requires the "enthtow port data pactiage." described in sice. III-(C..3!

Card No. 9 (Format: $4($ (fix, Fl2.s))

$S(X=$ the mesh ondiguration flag. where: $11.0)=$ a rectangular mesh. $1.0=$ a semicircular mesh.

$0 . M=$ w. the werrelasution parameter, ustaally 1.5.

$X^{\circ}=1$ the kinematic viseosity conefficient

BFIA $=x$. the coefficient of thermal expansion.

(ard No. 10 (Format: $4(6 x$, F12.5))

(i) $=g_{\mu}$. the savity aceleration.

AI. [ $^{2} \mathrm{HA}=$ = a coeftirient in tl" domor coll expressions.

BTA $=f_{1}$, a coeflicient in the domor cell expressions.

TFACT = the factor for altering it sser Sec. IIi).

Card No. 11 (Format: f(bx, Fi2.5))

$\mathrm{TCX}=\Xi$ the truncation error factor in the temperature equation.

$\mathrm{CEl}^{\prime}=2$ the cuncergence criterion for the pressive iteration.

$\mathrm{VOP} \mathrm{PL}=$ the velocity vector plot flag. where:

$$
0.0=\text { no vector plots. }
$$$$
1.0=\text { vector plots. }
$$

$\mathrm{NM}=$ the velocity vector scaling factor for plots. The scaling const ant is $\mathrm{VC}=(\delta \mathrm{r}+\delta z) /(2 \mathrm{~V}))_{\text {. }}$

Card No. 12 (Format: $4(6 x$, F12.5))

CXPLT = the contour plot 1lag. where: $0.0=$ no contour plots. $1.0=$ contour plots.

TFIN = the problem time to finish.

TDMP = the tape dump flag. where: $0.0=$ no tape dump. $1.0=$ tape dump.

DTCP $=$ the central processor $(C P)$ time in seconds between tape dumps (defäult $=$ DTCP $>$ the time limit requested on job card).

Card No. 13 (Format: 6(6x, I6))

INUIM $=$ the number of integer quantities stored in the NPLT array. 
$\mathrm{IBR}=\overrightarrow{\mathrm{I}}$, the maximum number of interior fluid cells in the radial direction $(\equiv \mathrm{R} 2) / \delta \mathrm{r}$ ).

$\mathrm{JBR}=\overline{\mathrm{J}}$, the maximum number of interior fluid cells in the axial direction $\left(\equiv .2 T / \delta z_{1}\right)$.

NPR = the number of cycles between prints on paper.

NPL $=$ the number of cycles between piots on microtilm.

NWR $=$ the number of cycles between writes on microtilm.

\section{Card No. 14 (Format 6(6x, I6))}

LPR $=$ the long print flag. where:

$1=$ no long prints on paper.

$2=l_{u_{i}}$ prints on paper.

LWR $=$ the long write Hag, where:

$1=$ no long writes on film.

$\underline{\underline{ }}=$ long writes on film.

The final set of datti is optional and varies in con10 nt fir different problems. Included in this set are the requirements for spectal constant temperature. intlow, and outflow boundary serments. For each scument. two data cards are required. The tirst comtaiass courdinates of the segment. $R_{\mathrm{I}, \mathrm{T}}, Z_{\mathrm{HT}}$. $\mathrm{R}_{\mathrm{RT}}$, and $Z_{\text {TW }}$ (Figr. fi). The second includes the appripriate values of velocity and temperature. The datat requirements for the three boundary types are:

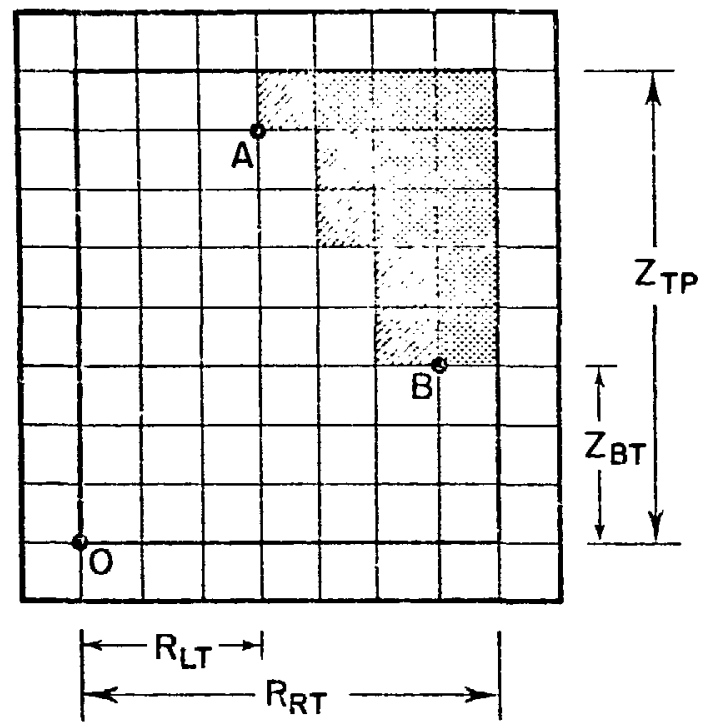

Fig. 6.

The' spatial dimensions needed for applying special boundary conditions on the cavity walls between points $A$ and $B$. The shaded area indicates the special fictitious cells required in the calculation. The dotted area includes cells flasged as special boundary cells but not used.
1. Constant Temperature Walls.

Card No. 1 (Format: 6x, 12)

$\mathrm{NCP}=$ the number of constant temperature scoments.

(ard No. 2 (Format: $4(6 x$, F12.5))

$C P C=$ the segment coordinates. $\mathrm{R}_{\mathrm{ITT}} . \mathrm{Z}, \mathrm{kT}$.

$\mathrm{R}_{\mathrm{RT}}$, and $\mathrm{Z}_{\mathrm{TT}}$.

Card No. 3 (Format: 4((ix, F12.5))

TPL = the specified temperature for the segment.

IThis set contains $2 \mathrm{NCl}^{\prime}+1$ cards. The remaining cards are of the same form as ('ards 2 and 3 and are arranged in the same order.)

\section{Inflow Boundaries.}

Card No. 1 (Format: (ix, 12) $\mathrm{NIP}=$ the number of intlow ports.

Card No. 2 (Format: 4(tix, F12.5))

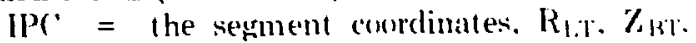
$R_{k i T}$. and $Z_{i T r}$.

Card No. 3 (Firmat: $4(6 x$, F12.5))

IPI $=$ the radial component of the inflow velocits:

Vil $=$ the axial component of the intlow velucils:

TPI = the spectied temperature for the segrment.

(Additional inflow segments require cards like Cards 2 and 3. The complete set of data for intlow ports contians 2 NIP +1 cards. $)$

3. Outflow Boundaries.

Card No. 1 (Format: 6x, I2) NOP = the number of outhow ports.

Card No. 2 (Format: $4(6 x, F+2.5))$

$O P C=$ the segment coordinates. Ri:r, $Z_{k \%}$. RkT and $Z_{1 T}$.

Card No. 3 (Format: $4(6 x$, F12.5))

$I^{\prime} P()=$ the radial component of outflow velocits.

$V P O=$ the axial component of outflow velucits.

(Fach outflow port calls for additional cards like 2 and 3. The complete set includes $2 \mathrm{NOP}+1$ (arcis.)

\section{Output Options}

CIRCO) results are recorded on printer palper and microlilm. The printer information incluctes the input data. long lists of values of the cell variables, and short prints containing the time, rele number. number of iterations per cvole, and maximum velucity in the sustem. The input dat a are printed at the start of the calculation. whereas the long lists and short prints occur every NPR number of time siteps. 
Tho same information also appetass on microlihn tosether with comtour plots of the primary variables and velucity rector plots. The number of creles between long lists on film is given by NWR, and VIl. is the number af cycles between plots. The short print information appears every cycle.

The code can autumatically provide lemer lists on paner and film of the initial cell data and those at crcle 1. Farch long list contains i, j. $\mathrm{FL}_{\mathrm{i}, \mathrm{j}}, \mathrm{u}_{\mathrm{i}+1.2 . \mathrm{j}}$. $v_{i, 1}+1, \ldots, p_{i, i}, D_{i, j}$, and $T_{i, j}$, in that order. for every cell in the computing mesh. Appropriate headings are provided for easy identification.

The nicrofilm plots are optional: velocity vector pluts are provided when VCTPL $=1.0$ : cont our plots of pressure and temperature. when CNPIT $=1.0$. The velocity plots show the flow direction and relative magnitude by plotting the scoled velocity at each cell cenier. Two types are avalable. one involving a constant soaling factor that depends on the iuput value VM. the other involving scaling that is cletermined by the naximum velocity in the system. In the latter. the vector length is determined sil as not to exceed a celi dimsision.

For each contour plot. the matrix of cell values is scanned to determine the ininimum and maximum. Then. allowing for 21 lines, the contour interval is determined using the minimum and maximum limits. The contour lines are formed by joining mints of equal value (interpolated between cell conters) with line segments. These plots contain the letters $\mathrm{L}$ and $\mathrm{H}$. which designate the locations of the mininum and maximum contotir values, respectivels.

\section{F. Magnetic Tape Restarts}

('lkC') can store data on magnetic tape at selected times cluring a run to permit restarting the problem from the stored information. The cell quantities and necessary problem constants are dumped on tape periodically during normal running of the corle. The dump frequency is controlled by input yuantities. DTCP and TFIN, and the time limit requested on the job card. Dumps are provided at regular iniervals of eiapsed central processor time by specitying DTCP to be the number of seronds hetween dumps. Also. when the calculation reaches the problem time to finish ( $=$ TFIN), a dump is autumatically taken. If the time limit respuested on the job card is reached before $t=$ TFIN. a dump is provided shortly before the time limit is exceeded.

To suppress the use of magnetic tape, DTCP and TFIN must be set to values in excess of those anticipated for computer time and problem time. respectively. Specifying $\mathrm{TDMP}=0.0$ in the input dilla suppresses the dump just before the computer time request is exceeded.

Two options are available upon restart from tanc: either the problem is continued using the data stured in tape, or the input dat a for the problem require changes and new dat a cards must be read (see Ser. III-C). In the latter ease. provision is made to change input quantities. but the data for the cell variables are the information stored on tape.

\section{NUMERICAL EXAMPLES}

This section presents the results of three applications of CIRCO to buoyancy-driven circulation within a rigid spherical cavity. Examples serve to familiarize the reader with CIRCO's capabilities and to show graphical code output. They re!ate specifically to Pacer project investigations and include, in order, working fluid circulation initiated: - From the bouyancy induced by a localized hot region, which is the result of nonuniform distribution throughout the working fluid of heat from a single explosion.

- From the buoyancy induced by removing heat from the working fluid through heat exchangers, and - From forced convection and buoyancy induced by withdrawing the heated working fluid into heat exchangers and returning the cooled fluid to the cavity.

\section{A. Nonuniform Deposition of Heat Energy from an Explosion}

The first example is buoyancy induced by an explosion in the cavity, in the absence of heat exchangers and forced convection. The explosion distributes heat energy unevenly, but the corresponding deposition of momentum is ignored. To represent the initial conditions, a heated, $600^{\circ} \mathrm{K}, 50-\mathrm{m}$ radius spherical region is located on the axis $75 \mathrm{~m}$ from the bottom of the 200 -m-radius spherical cavity. The initial temperature of the surrounding fluid is $500^{\circ} \mathrm{K}$. As the buoyant fluid rises, clockwise circulation is produced. Gradually the temperature of the initially heated fluid decreases, the buoyant fluid hits the top of the cavity, and the circulation slows.

In this calculation, $I B R=40$ and $\mathrm{JBR}=80$, so $\delta \mathrm{r}=\delta \mathrm{z}=5 \mathrm{~m}$. In this and the examples to follow, the heat conduction cuefficient is constant, $\mathrm{K}=1.25$ $\mathrm{m}^{2} / \mathrm{s}$, and the coefficient of volumetric expansion is $\beta=0.002 /{ }^{\circ} \mathrm{K}$. Initially the fluid is at rest. The temperature gradient is depicted in the contour plot of Fig. 7. which shows the relative location of the 


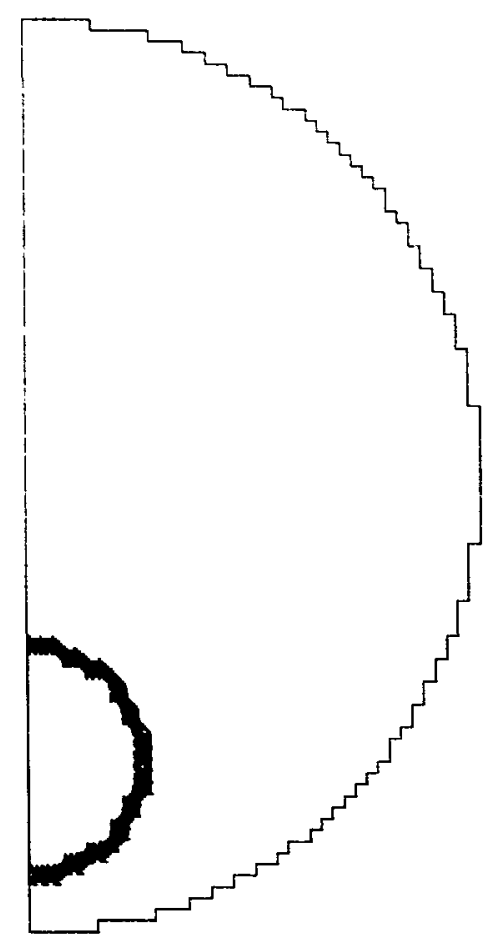

Fig. 7 .

The initial temperature contour plot showing the location of the heated region in the cavity.

- heated region in the cavity. Figure 8 is a composite that shows the state of the fluid at $t=20,50$, and 70 $s$. These plots show the outline of the cavity region in the $\mathrm{r}-\mathrm{z}$ cross section. The top row depicts the velocity vectors: the middle row, the temperature contours (isotherms); and the bottom, the pressure contours (isobars) at the three times.

At $\mathrm{t}=20 \mathrm{~s}$, the induced circulation, as indicated in the velocity vector plot, is clockwise. The maximum velocity in the system, $v_{\max }$, is $16.9 \mathrm{~m} / \mathrm{s}$. By this time, the maxinum temperature, $T_{\max }$, is $577^{\circ} \mathrm{K}$. Associated with the vortex center of the circulation is a low-pressure region, whereas a highpressure region develops at the top of the heated region. The heated fluid continues to rise until, by 50 $s$, it has reached the top of the cavity and expanded radially to form a torus. A clockwise circulation is still maintained; however, $v_{\max }$ is $9.5 \mathrm{~m} / \mathrm{s}$. $T_{\max }$ at this time is $516^{\circ} \mathrm{K}$. The low-pressure region is still associated with the vortex center of the circulation. At $70.0 \mathrm{~s}$, the fluid motion has slowed: $v_{\max }$ is 4.6 $\mathrm{m} / \mathrm{s}$. The heaied fluid continues to follow the cavity wall. It has cooled to a $\mathrm{T}_{\max }$ of $511^{\circ} \mathrm{K}$. The low- pressure region remains closely assuciated with the vortex center.

\section{B. The Presence of a Cooling Plate}

The second example is circulation induced by the presence of a cooling plate off the cavity axis. The cavity is again $200 \mathrm{~m}$ in radius, and the working lluid is initially at a uniform teneperature of $550^{\circ} \mathrm{K}$. The cooling plate is kept at $300^{\circ} \mathrm{K}$ throughout the calculation. For this case, $\delta \mathrm{r}=\delta \mathrm{z}=10 \mathrm{~m}$.

Table I is the printout of the input data for this problem showing the additional information needed to define the cooling plate. This printout appears hoth on paper and microfilm.

The cooling plate is a toroidal section of a cap on the wall in the upper part of the cavity. Starting 130 ) $\mathrm{m}$ from the axis and extending to a radius of $160 \mathrm{~m}$, it is located $330-360 \mathrm{~m}$ above the hottom. Figure 9 shows the isotherm plot at cycle 1 when the fluid immediately around the plate is cooled to $524^{\circ} \mathrm{K}$. The temperature difference between the wall and the fluid induces a circulation that at first rotates generally clockwise in the $r-z$ cross-sectional plane. Subsequently, the circulation patterns become very complex showing breakup and coalescence of eddies within the cavity. This behavior is seen in Fig. 10 , which shows the velocities at $120 \mathrm{~s}$ (200 time steps) and $520 \mathrm{~s}$ (1000 time steps). The maximum velocity at $120 \mathrm{~s}$ is $11.1 \mathrm{~m} / \mathrm{s}$; that at $520 \mathrm{~s}$ is $5.1 \mathrm{~m} / \mathrm{s}$. The circulation pattern at the later time shows that the single large vortex formed initially breaks up into a series of vortices that continue to interact, causing further breakup and coalescence.

\section{Forced Convection}

The final sample calculation is that of coupled forced convection and buoyancy in which working fluid is withdrawn from the cavity at $1450 \mathrm{~kg} / \mathrm{s}$. Fluid, cooled to $100^{\circ} \mathrm{K}$ after passage through a heat exchanger, is introduced through a one-cell opening at the top left of the computing mesh. The heated fluid is withdrawn through an adjacent cell. This configuration represents inflow and outflow through coaxial cylindrical pipes.

Unlike the circulation patterns observed in the cooling plate problem, this calculation shows a counterclockwise circulation in the $r-z$ plane. The general pattern formed in the first 5 min of cavity operation is maintained throughout $12 \mathrm{~h}$ of operation. Furthermore, there is no short-circuiting of the 

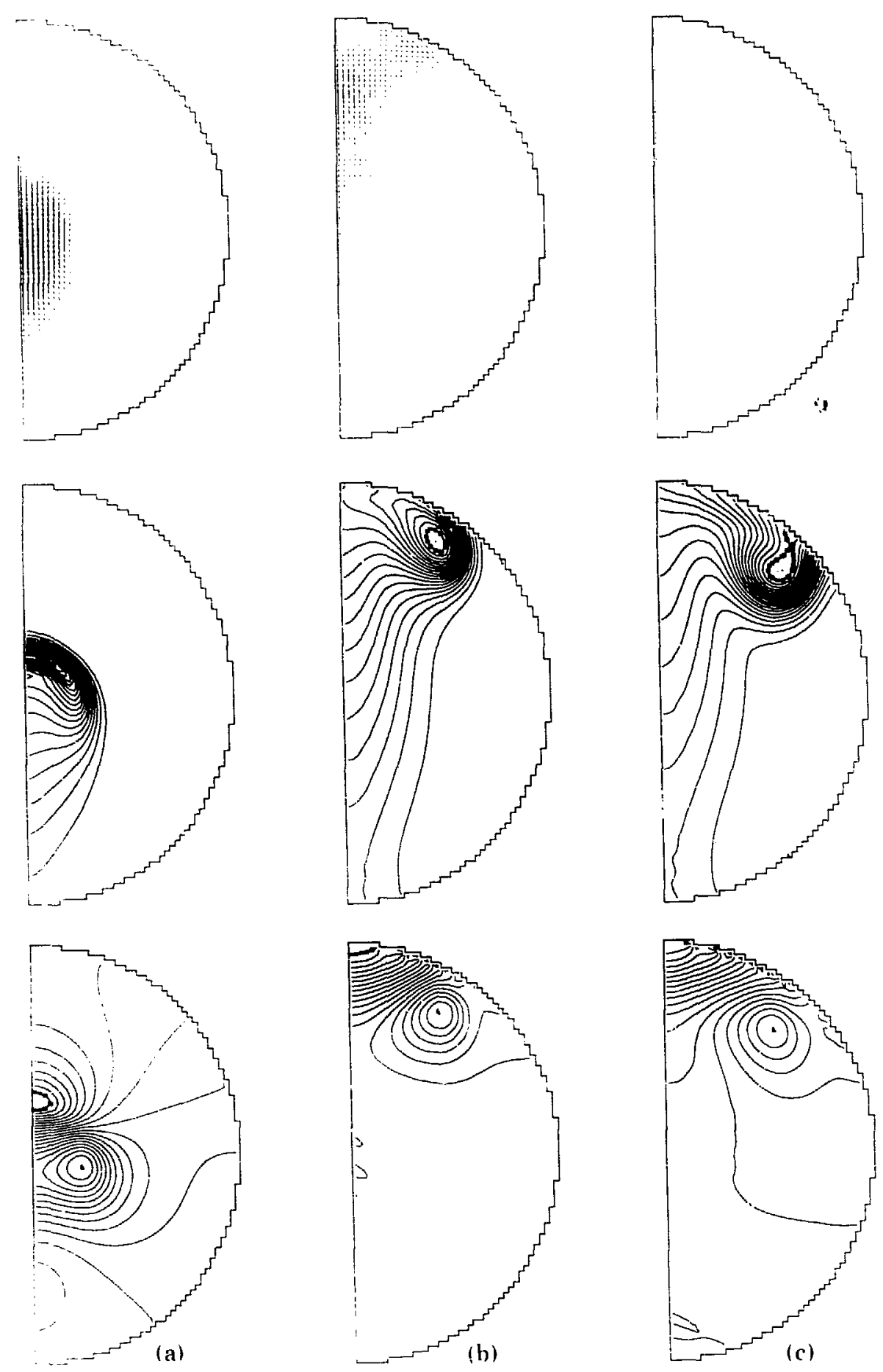

Fig. 8.

A composite of velocity vector and temperature and pressure contour plots showing the state of the fluid whose circulation was initiated by an uneven distribution of heat energy in the cavity: (a) $t=20 \mathrm{~s}$, (b) $t=50 \mathrm{~s}$, and (c) $t=70 \mathrm{~s}$. 
TABLE I

CIKCO INPUT DATA

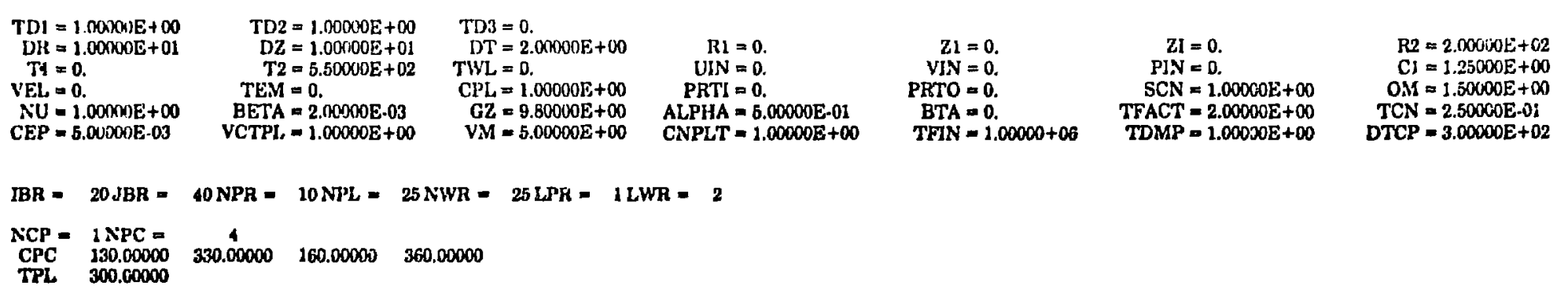




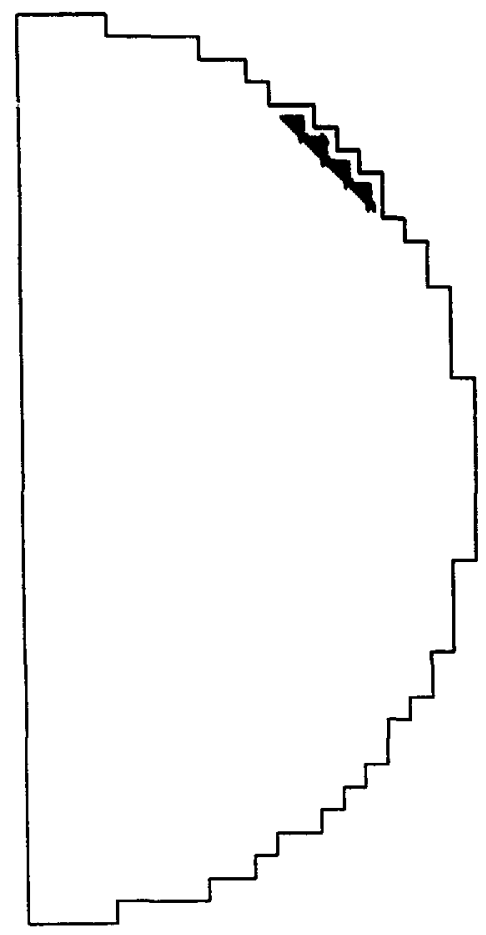

Fig. 9.

The initial isotherm plot showing the location of the cooling plate on the cavity wall.
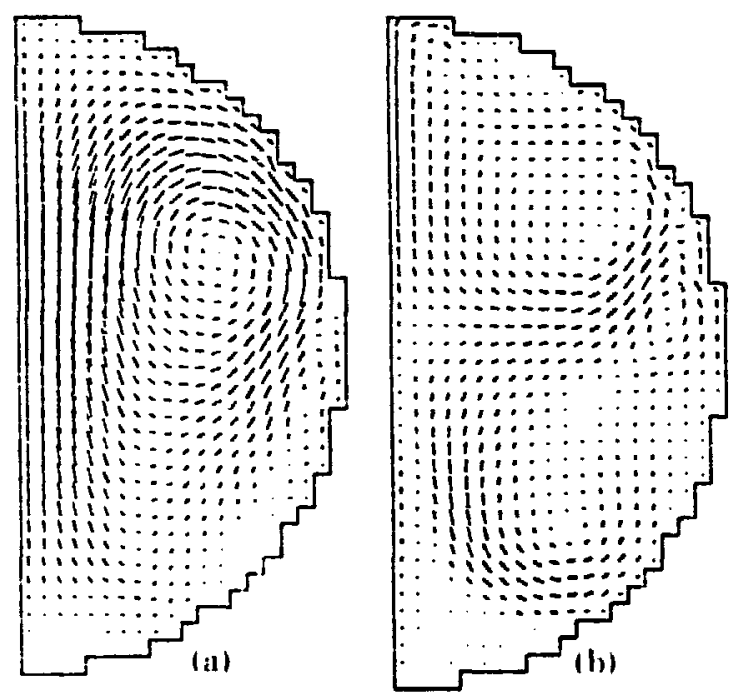

Fig. 10.

Velocity vector plots of the induced cir. culations caused by a cooling plate: $(a) t=120$ $s$ and $(b) t=520 \mathrm{~s}$. cooled fluid from the inflow to the outflow purts, which indicates the likelihood of efficient cavity cooling.

Figure 11 summarizes the results of this calculation by showing the velocity vectors and temperature contours at 1 and $12 \mathrm{~h}$ during cavity operation. The cooled fluid introduced on the cavity axis accelerates as it flows down the axis to the bottom. The velocity at the inflow port is beld constant at $0.17 \mathrm{~m} / \mathrm{s}$. After $1 \mathrm{n}$ of operation, the maximum velocity in the cavity is $6.8 \mathrm{~m} / \mathrm{s}$, and it is still $6.6 \mathrm{~m} / \mathrm{s}$ after $12 \mathrm{~h}$ of operation. At $\mathrm{t}=12 \mathrm{~h}$, the average cavity temperature is $532^{\circ} \mathrm{K}$, duwn from the initial $550^{\circ} \mathrm{K}$. The isotherm plots at the two times are similar in shape, the maximum cell temperature being $552^{\circ} \mathrm{K}$ and the minimum $492^{\circ} \mathrm{K}$ after $1 \mathrm{~h}$. These temperatures reduce to 533 and $474^{\circ} \mathrm{K}$, respectively. at $12 \mathrm{~h}$.

\section{ACKNOWLEDGMENTS}

We thank Francis H. Harlow for his many valuable contributions to development of the code.

\section{REFERENCES}

1. F. H. Harlow and J. E. Welch. "Numerical Calculation of Time-Dependent Viscous Incompressible Flow," Phys. Fluids 8, 2182 (1965): J. E. Welch, F. H. Harlow, J. P. Shannon. and B. J. Daly. "The MAC Method: A Computing Technique for Solving Viscous, Incrimpressible, Transient FluidFlow Problems Involving Free Surfaces." Los Alamos Scientific Laboratory report LA-3425 (1965).

2. A. A. Amsden and F. H. Harlow, "The SMAC Method: A Numerical Technique for Calculating Incompressible Fluid Flows," Los Alamos Scientific Laboratory report i 1.4370 (1970).

3. R. G. Shreffler and R. E. Roush, "PACER Program FY-1974 LASI, Activity." Los Alamos Scientific Laboratory report LA-5i54-MS (1974).

4. C. W. Hirt and J. L. Conk. "Calculating ThreeDimensional Flows around Structures and over Rough Terrain." J. Comp. Physs. 10, 324-340 (1972).

5. W. C. Rivard, O. A. Farmer. T. D. Butler, and P. J. O'Rourke. "A Method for Increased Accurncy in Fulerian Fluid Dinamies Calculat jons." Ins Alamos Scientific Laboratory report L.A-5426-MS (1973). 

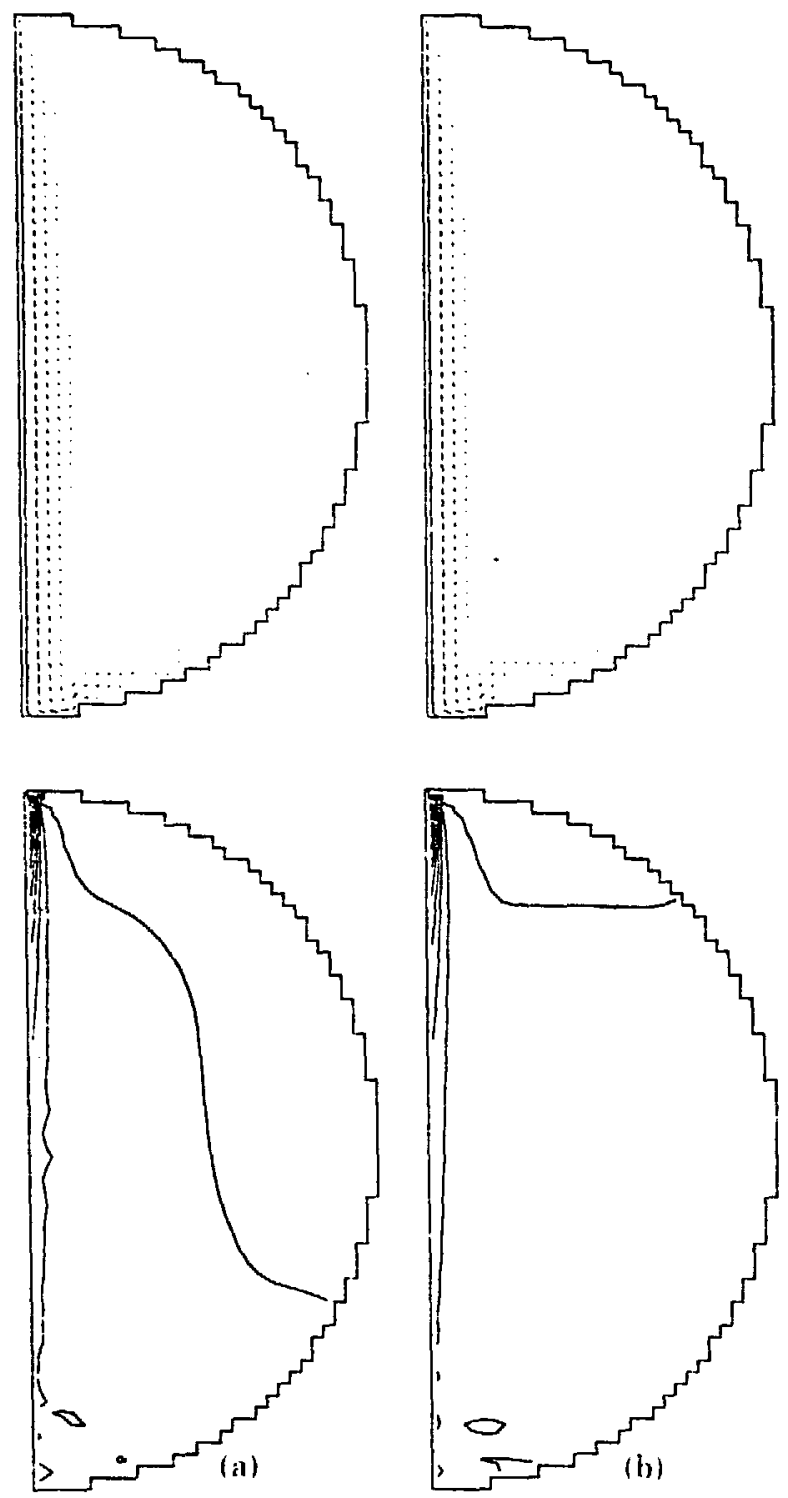

Fig. 11 .

A composite of velocity vector and isotherm plotss shor:ing the effects of adding cooled fluid and withdrawing heated fluid through inflow' and outflou ports in the cavity walls: $(a) t=1$ $h$ and $(b) t=12 h$. 


\title{
APPENDIX
}

\section{FORTRAN IV INDEX LISTING OF THE CIRCO PROGRAM}

\author{
LASL CODE NO. LP-0550
}

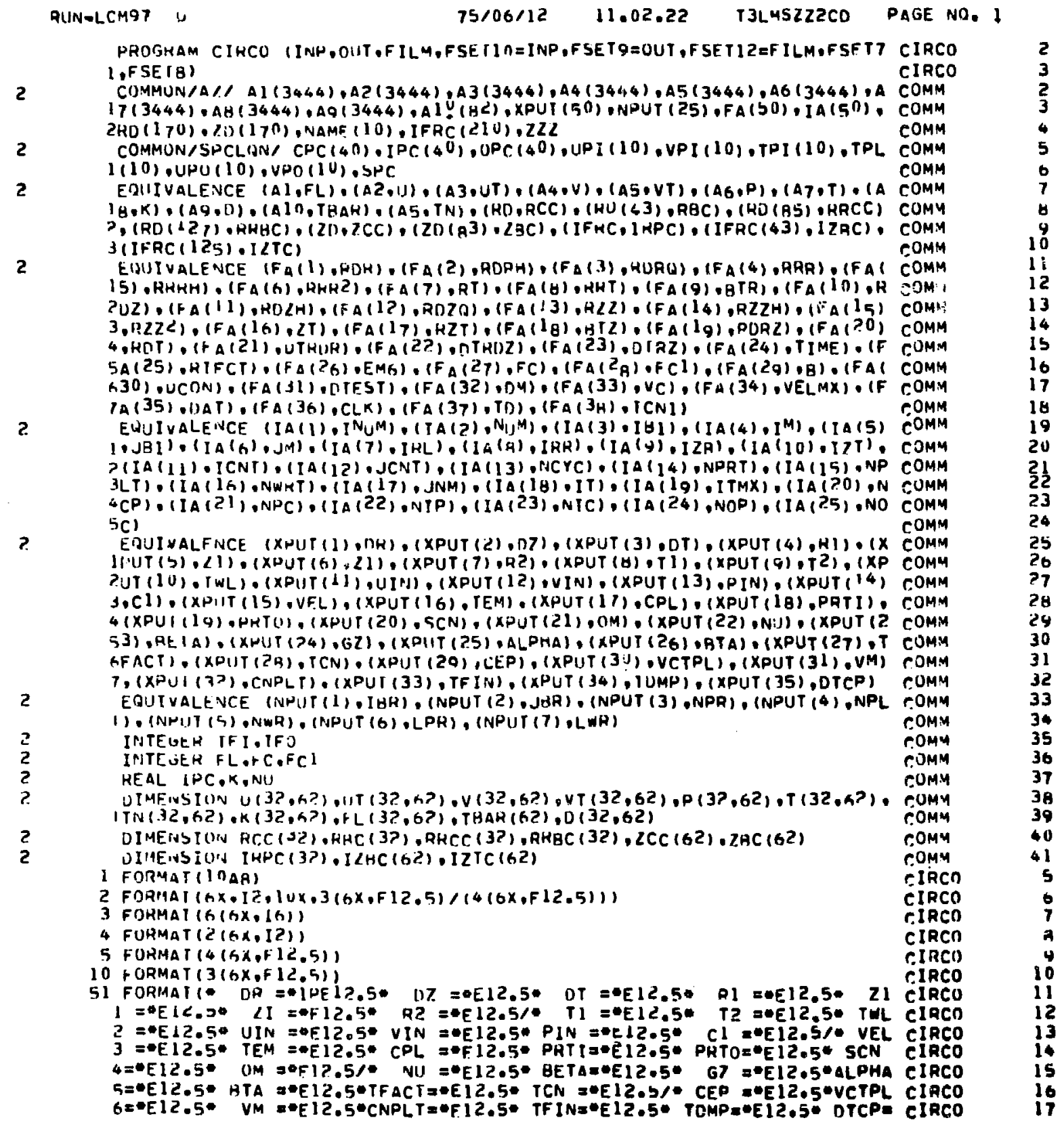




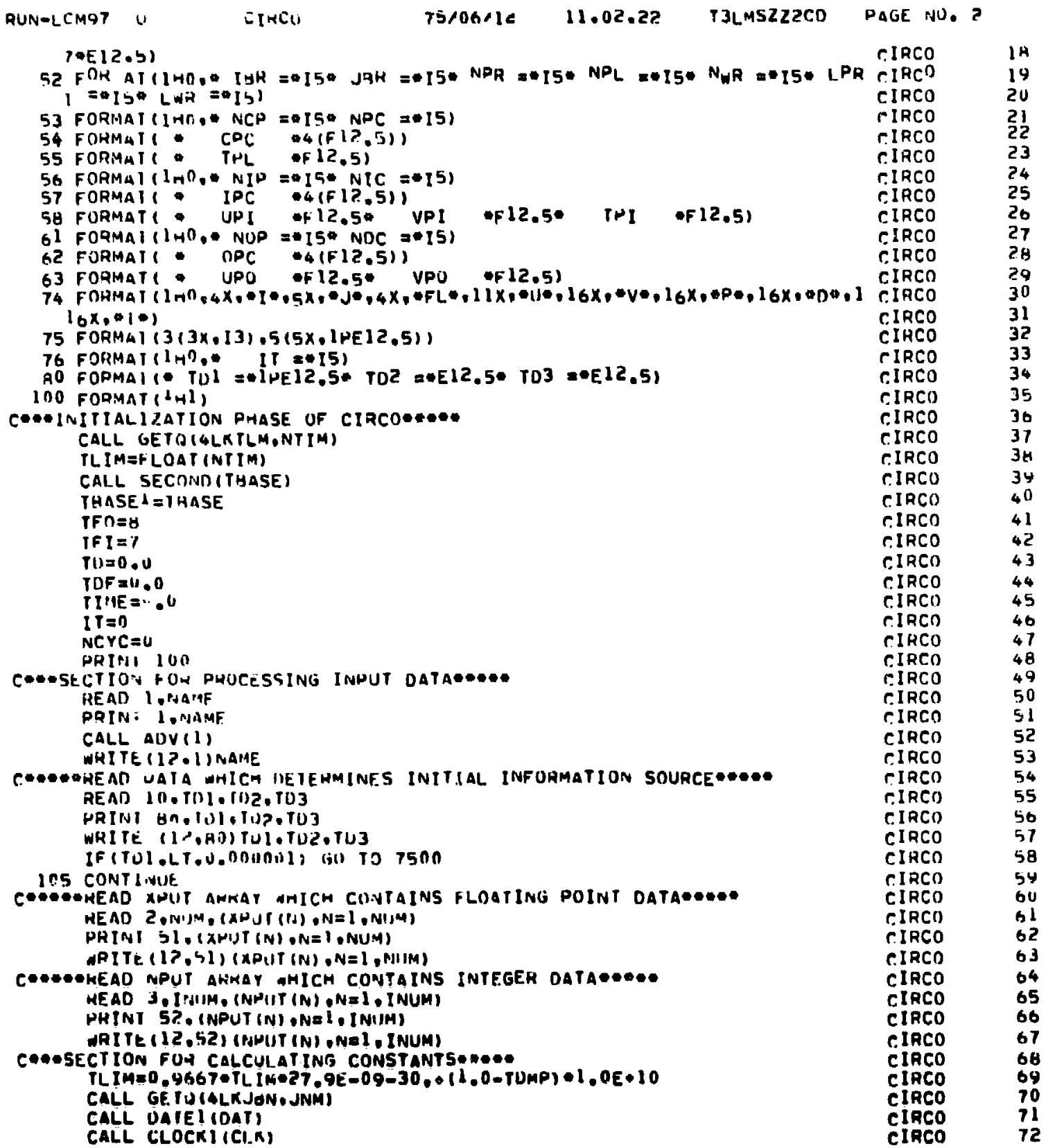


RUN-LCHAT U

CIHCO

$75 / 06 / 12$

11.02 .22

T3LNS2Z2CD

PAgE NO. 3

201

201

201

?01

201

?nl

2ก1

$2 n 1$

2n!

201

201

201

201

201

201

234

243

243

243

250

257

257

257

263

243

253

263

263

263

263

263

2.77

306

306

3 ns

313

313

313

313

313

313

313

313

313

313

313

350

353

353

353

353
$E M 6=1 . n E-116$

Iri $=\lfloor\mathrm{HH}+1$

$I M=I \Delta H+2$

$J B]=J H K+1$

$J M=J a H+?$

$V C=(U H+[1) \angle) /(2 . \forall M)$

HTFCI $=1.1 /$ TFACT

C*A*OOR DEPENIIENI CONSTANTS * *

AUR $=1,0 / 11 \mathrm{R}$

RRR $=1.0 / 11 R=\square 2$

HLIHH $=0.5 \%$ RUH

R() $D D=0.25 \circ$ DUH

HRRH $=0.54 \mathrm{HAH}$

RI?RZ $=2.0$. HHH

$R T=I$ INQUH

HRT $=1.0 /$ T

UO lod $I=1,1 \mathrm{~N}$

$\operatorname{RCC}(I)=(1-1.5) \cdot D H$

$R H C(1)=(1-1.0) \triangle D R$

150 CONT INUE.

DO $155 \quad I=2.1 M$

RHCC $(1)=1.0 / \mathrm{KCC}(1)$

RHAC $(1)=1.0 / \mathrm{KHC}(1)$

155 CUNTINUF

C*A.OUZ DEPENIIENT CUNSTANTS*

RDT $=1.0 / 112$

$K Z Z=1-0 / 1) / *+2$

$\mathrm{HDZH}=4.54 \mathrm{WN} /$

ADZO $=0.25 \times H 112$

$K Z 7 . H=0.50 \mathrm{HLL}$

HZIT: $=2.0$ QRLL

$\angle T=J H A * C L L$

$R Z T=1, n / 2 r$

Do lo: $J=1, \mathrm{JM}$

$\angle C C(J)=(J)=1.5) \circ 02$

$\angle B C(J)=(1-1.0,01)$

160 CONTINUTF

RORZ $=$ HIH $O$ HODL

$D C O N=(7-0 \circ C E P) /(D H+O Z)$

C***0T DEPENIENT CUNSTANTS****

$R U T=1 . n>n T$

DTRDK=UT*HกA

UTAD $\angle=$ OT QHI)

UTRZ $=\angle .00 U T /(0 A+n Z)$

TCN $1=0.5 * 3 ! T *(1, n+T C N)$

$B=-(0.5 \bullet H O T \bullet O M) /(R H H+K \angle Z)$

HTR=BIADITAUK

$H T Z=\Delta T A \cap \cap T R U Z$

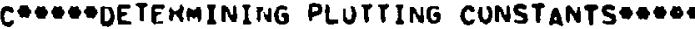
$D M=2$ I

IF (ZT.LT.RT) DMEAT

$\int A L=1<3$

IAA

ILTaYUO.-LT/UMEgOO. EMG

1283400
CIHCO 73

CIHCO $\quad 74$

CIRCO

CIRCO 76

CIRCO 77

CIRCO 78

CIRCO 79

CIRCO BO

CIRCO BI

CIRCO Bद

CIRCO

CIRCO

CIRCO A5

CIRCO bo

CIRCO Hi

CIRCO 88

CIRCO

CIRCO 90

CIRCO

CIRCO 92

CIRCO

CIRCO 94

CIRCO US

CIRCO 90

CIRCO 97

CIRCO 98

CIRCO

CIRCO 100

CIRCO InI

CIRCO 102

CIRCO 103

CIRCO 104

CIRCO 105

CIRCO Ins

CIRCO 107

cIRCo lng

CIRCO 109

CIRCO 110

Claco 111

CIRCO 112

CIRCO 113

CIRCO 114

CIRCO 115

CIRCO 116

CIRCO 117

CIRCO IIB

CIRCO

CIRCO 120

CIRCO

CIRCO 122

CIRCO 123

CIRCo 124

CIRCO 125

CIRCO 126

CIRCO 127 


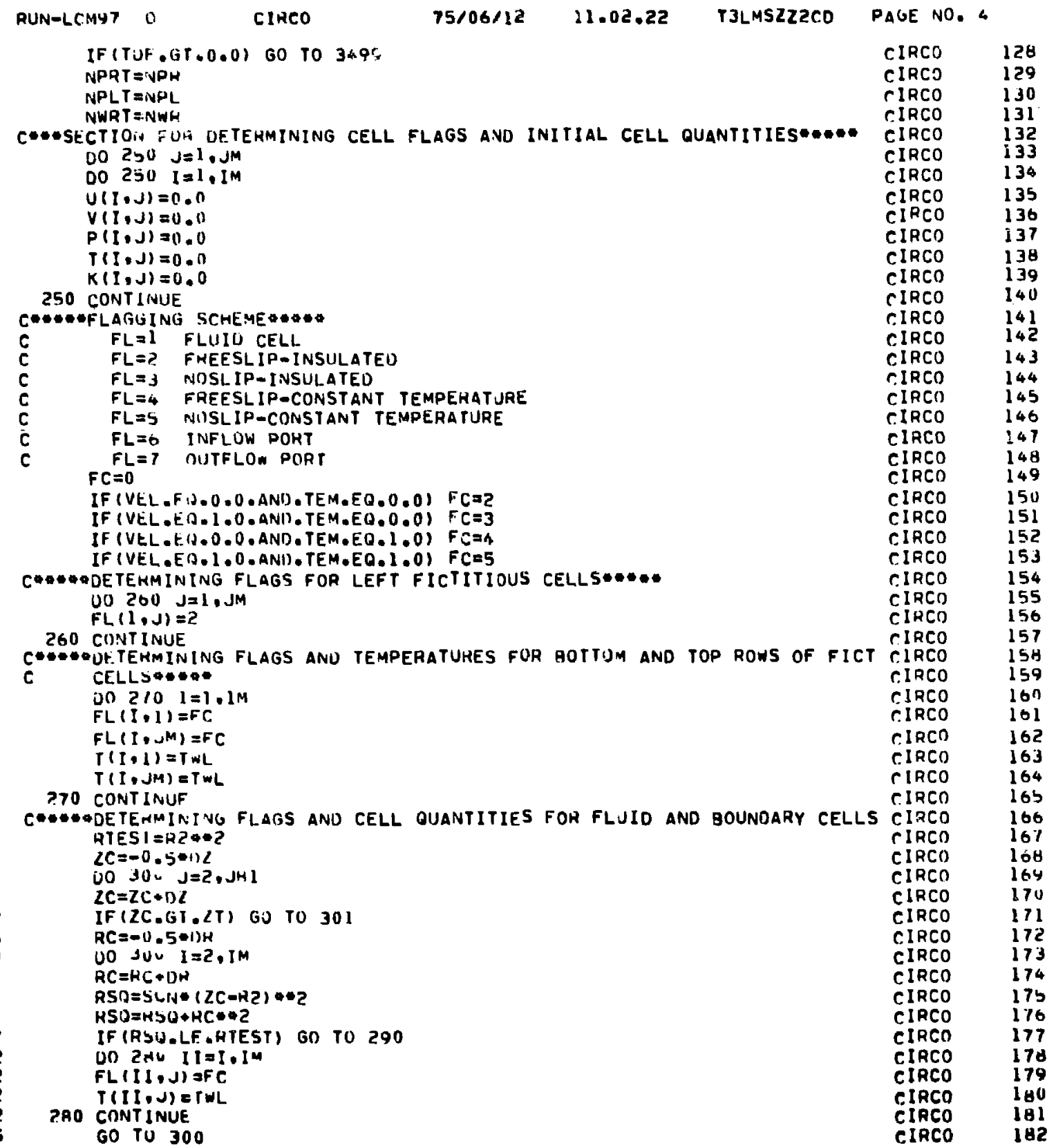


RUN-LCH97 J

PAGE NO, 5

$290+L(I, J)=$

$P(I, J)=P I N$

$T(I ; J)=1$ ?

300 CONT INUE

554

301 CONTINUTE

C**-*SETTING SPECIAL INTERIOR TEMPERATURES* ***

HTE.S $I=R I \bullet: 2$

561

S61

5 h5

566

5 h 6

566

574

500

6n2

604

605

$6 \cap 5$

605

613

62?

A?5

630

630

6.32

633

637

644

653

656

G61

GR?

664

665

675

705

715

717

717

717

717

725

7.35

765

755

764

773

1002

1002

1002

1002

1002

$2 C=-0.5 * 1) 2$

$0031+i=2, J d$

$Z \mathrm{C}=\mathrm{ZC}+\mathrm{DC}$

ZTESI $A=\angle 1-0.5 * \angle I$

ZTESI $2=\angle \mathrm{i}+0.5 * \angle \mathrm{i}$

IF (ZC.GT.LTFSTL) GO TO 312

IF (2C.LT.LTESTI) GO TO 311

$R C=-0.5 \% \mathrm{i} H$

DO $\$ \backslash \| I=2, I H I$

$R C=R C \cdot D H$

$R S D=S L N *(\angle C-\angle 1) \cup Z$

$R S D=K S Q+R C *-2$

IF (PSH-LE-RTEST) T(I.J) I I

310 CONT INUE

311 CONTINUE

312 CONT INUE

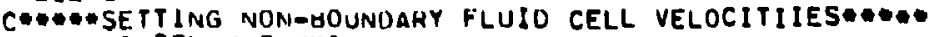

DO $325 \mathrm{~J}=\mathrm{P}, \mathrm{JH}$

00 320 I=?, I I I

IF (FL II,J).NE , I) GO TU 325

IF (FLII・I,J),E(U,I) U(I,J) IIIN

IF $(F L(I, J \bullet I), E,].) \quad V(I, J)=V I N$

320 CONTINUE

325 COHT INUE

$F C l=5$

IF (VEL.E').0.0) FCI=6

IF (CHL.E(2.0.0) कO TO 455

C***\#SETTING FI AGS AND TEMPERATURES FOR SPECIAL CONSTANT TEMPEHATURE CE READ 4,NCP,NPC

PHINT $23 . \mathrm{HCP}, \mathrm{HAOS}$

WFITL $(12,53)$ NCP.NPC

UU 4S: $N=1$, NCP

$M=4 *(N-1)+1$

i $1=M+1$

$M 2=M \cdot 2$

$M 3=M+3$

HF AD S. (CPC (NN), NNEM,M3)

PRINI 54 . (CPC (NN) , NN=M,M3)

WRITE (1 ? .54) (CPC (NN) , NNAM,M3)

REAU $\supset, 7 P L(N)$

PHINI 55,THL (N)

ARITE $(12.55)$ TPL (N)

$R C I=C H C(M)$

$\mathrm{ZCI}=\mathrm{CPC}(\mathrm{MI})$

$R C 2=C P C(M 2)$

$\mathrm{ZC2}=\mathrm{CHC}(\mathrm{M} 3)$

$2 C=-1.5 \oplus 02$

DO $450 \mathrm{Jal} . \mathrm{JM}$

CIRCO

183

CIRCO

EIRCO

C.IRCO

CIRCO

eIRCO

CIRCO

ClRCO

CIRCO

ClRCO

CIRCO

CIRCO

CIRCO

CIRCO

CIRCO

eIRCO

CIRCO

CIRCO

CIRCO

CIRCO

CIRCO

CIRCO

C.IRCO

PIRCO

CIRCO

(:IRCO

r.IRCO

CIRCO

r. IRCO

CIRCO

CIRCO

CIRCO

CIRCO

CIRCO

CIRCO

CIRCO

CIRCO

CIRCO

CIRCO

CIRCO

c. IRCO

IIRCO

CIRCO

CIRCO

circo

CIRCO

CIRCO

cIRCo

CIRCO

CIRCO

cIRCO

eIRCO

cinco

CIRCO

eInco

184
185

186

187

188

189

190

191

192

193

194

195

196

197

196

199

200

201

202

$2 n 3$

204

205

206

207

208

209

210

211

212

213

214

215

216

217

218

219

220

221

222

223

224

225

226

227

22B

229

230

231

232

233

234

235

236

237 


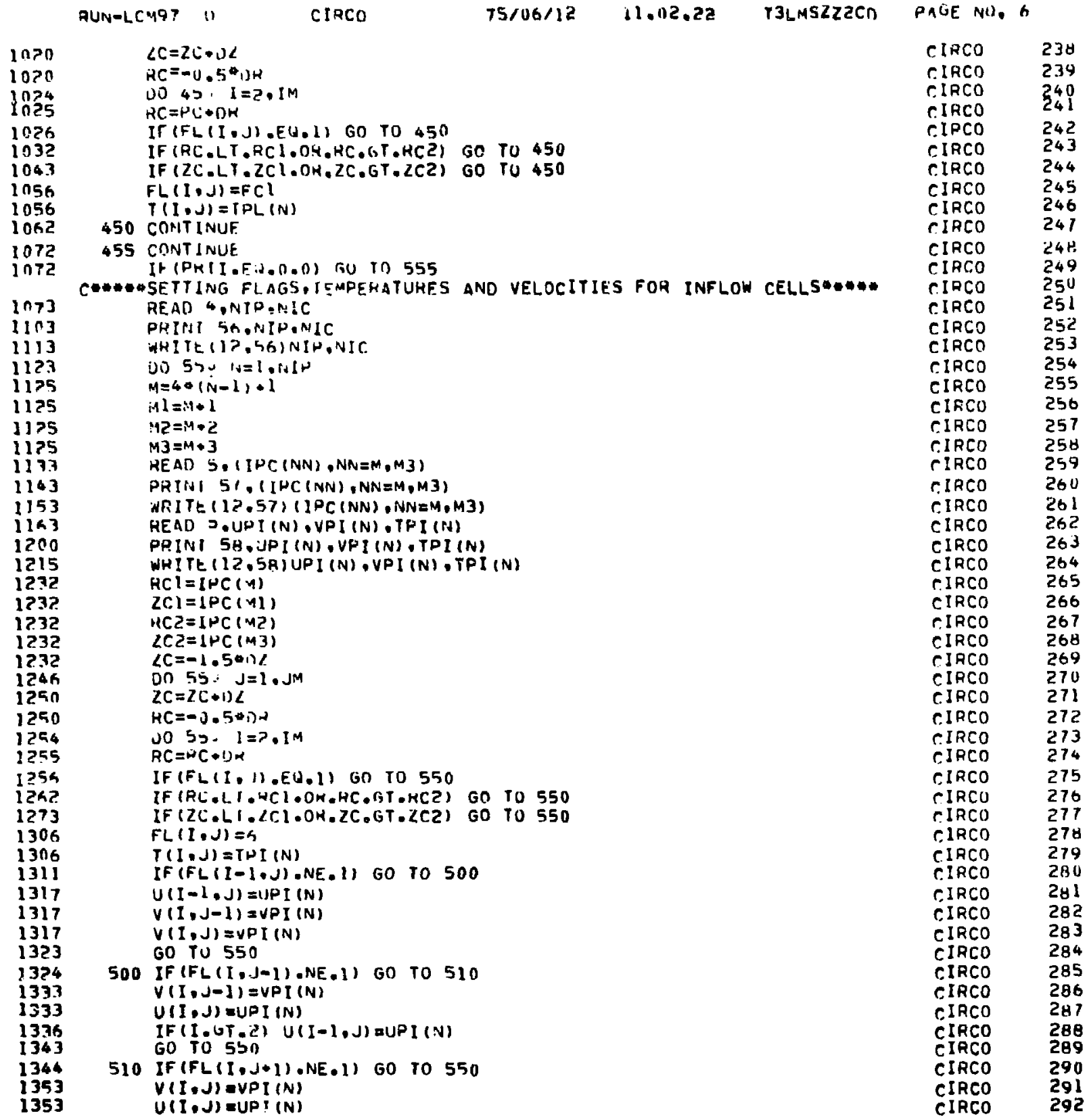




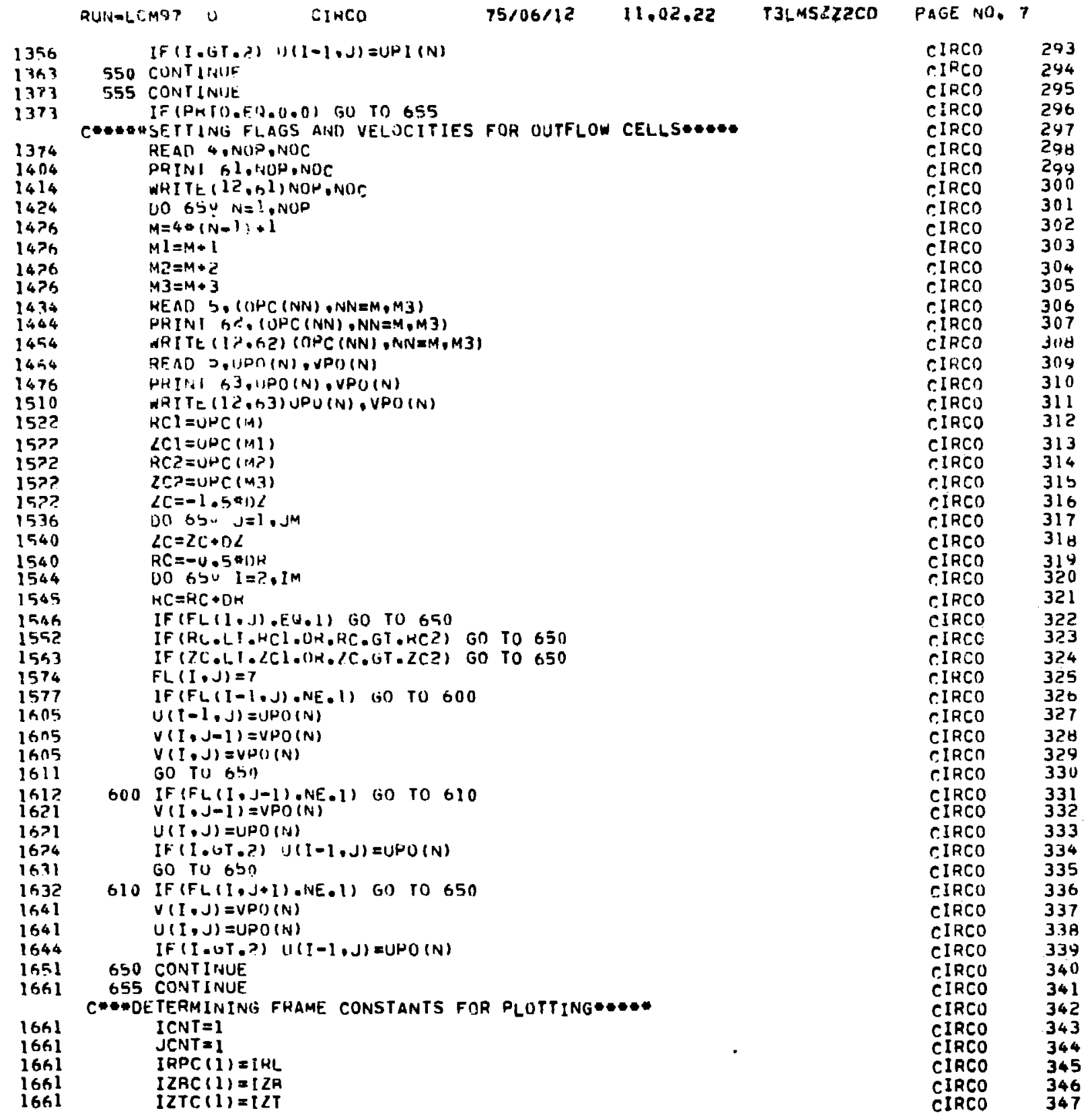




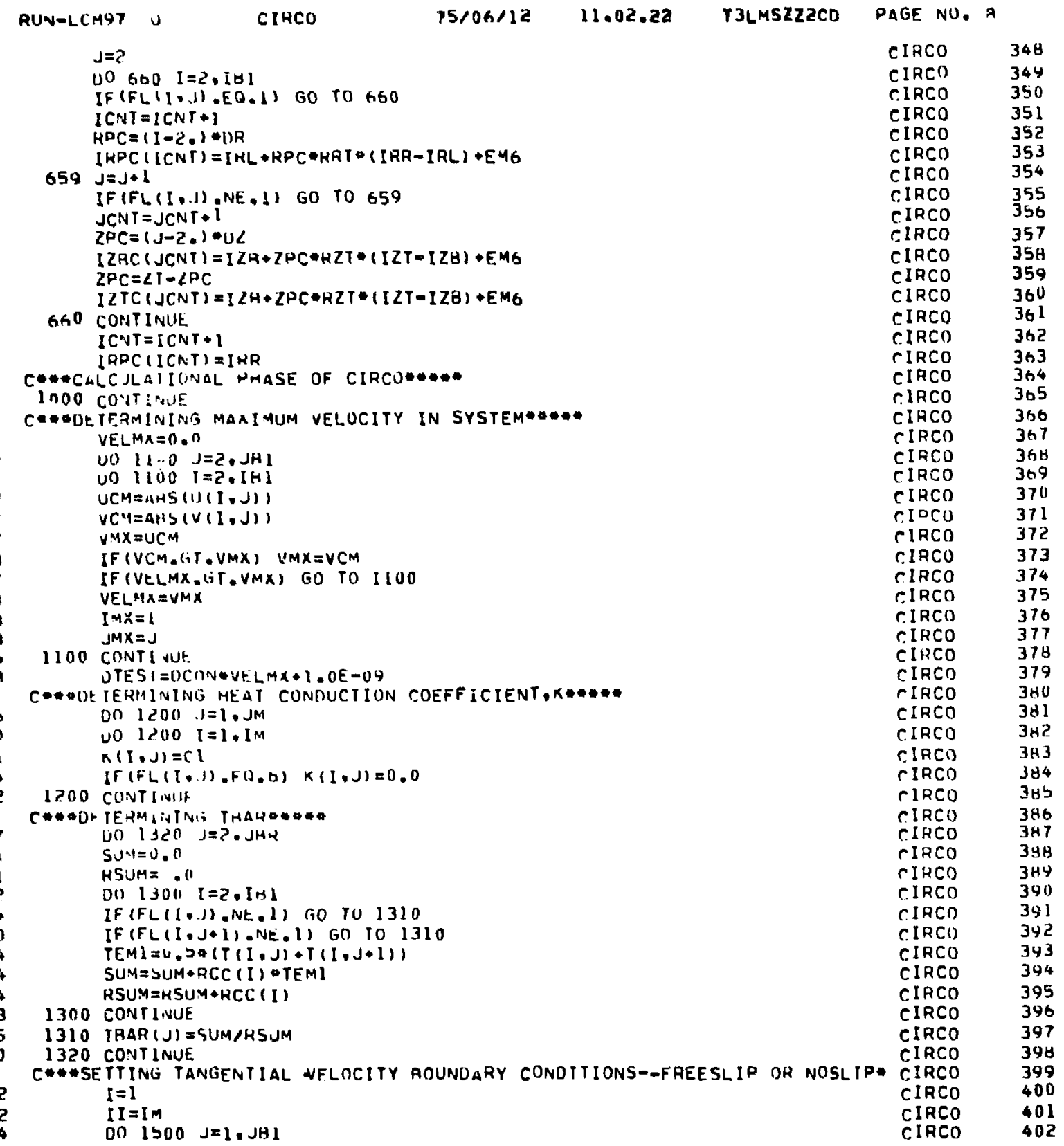




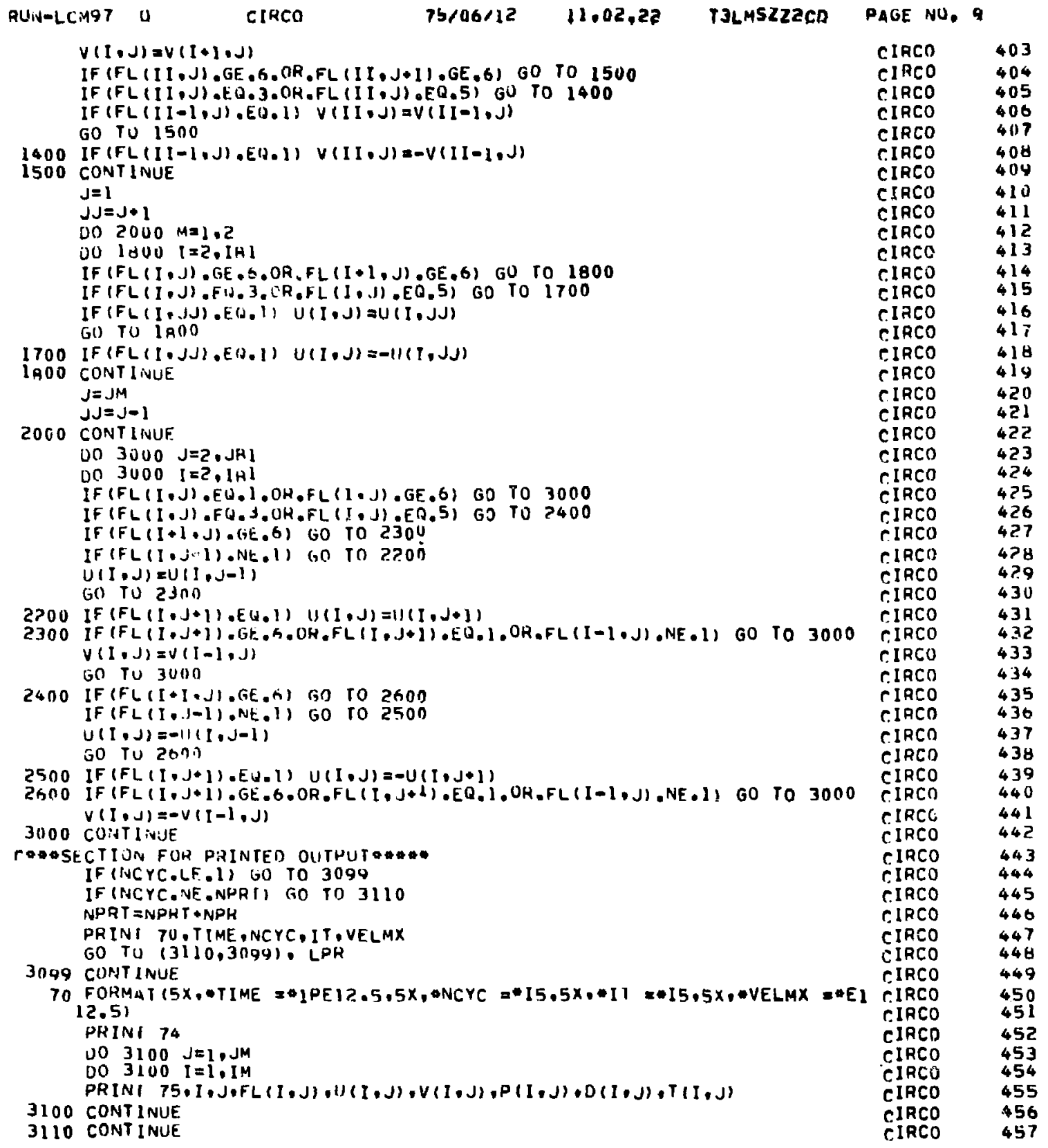




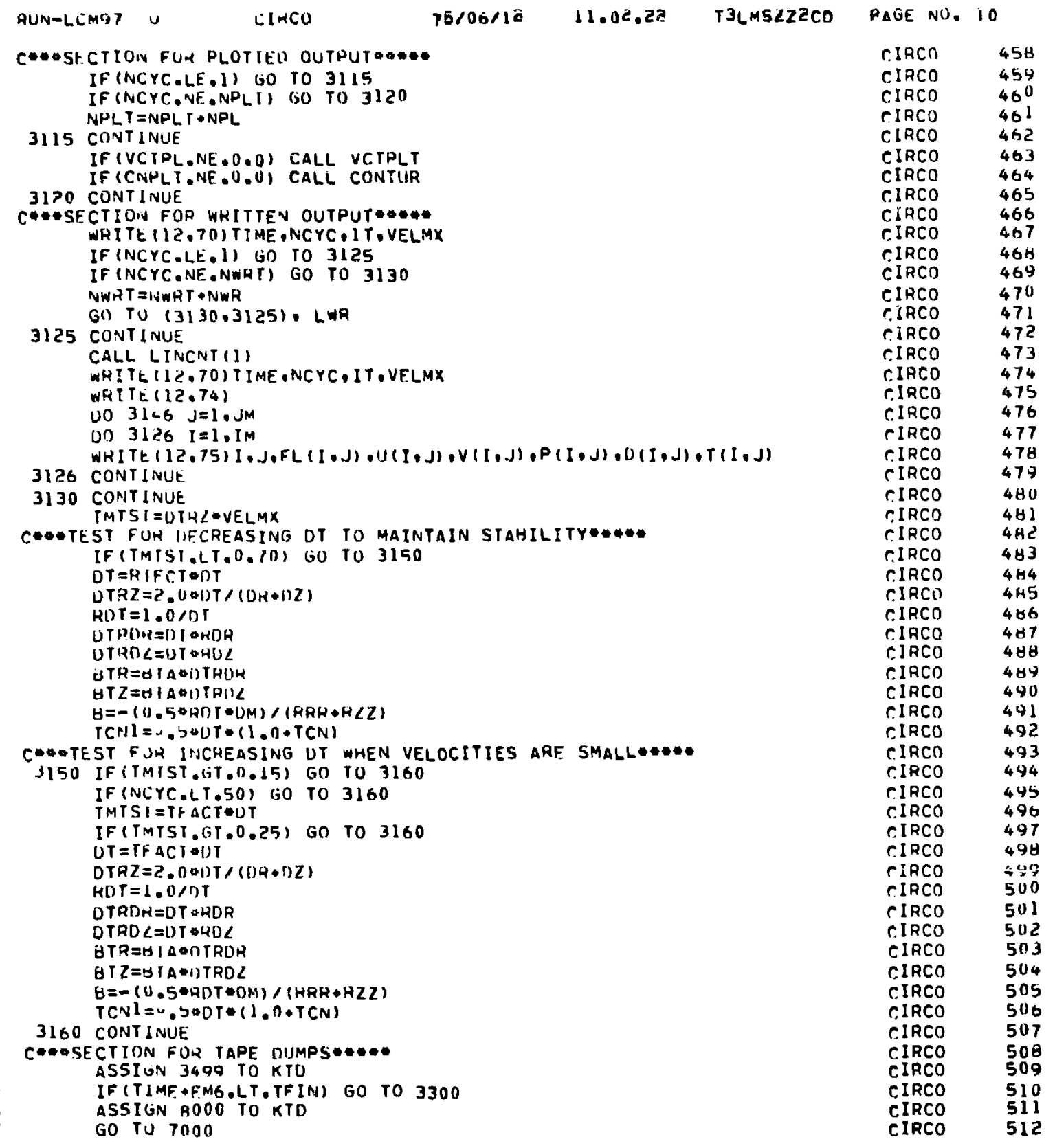


RIIN-LCMOT O

PAGE NO. 11

27??

2731

2735

2736

2736

2742

2742

2743

?74?

2743

2747

2750

2751

2755

2752

2762

P7k?

3762

2T62

27R2

7762

2762

2762

?.7K?

P762

276?

3 ก5

3061

3061

3041

3nal

उत:

3nal

3na!

3nal

3nkl

3061

3ORL

3 nal

3061

3161

3164

3167

3170

3171

3175

3203

3213
3300 CALL SEC NNRITCYC)

IF ( IICYC-THASE) LLT.TLIM) GO TO 3310

ASSIGN HOUOR TR KTO

Gn TO 7000

3310 IF ( ICYC-TAASE W).LT.DTCP) GO TO 3499

IASSE $1=$ TCYC

GO TO TONO

3499 CONTINUE

I I $M E=I\lfloor M F+D T$

NCYC $=N C Y C+1$

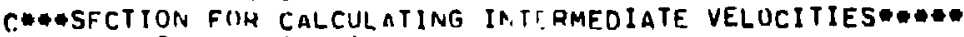

DO $3649 \mathrm{~J}=$ ?. JAI

UO 304 A $I=2$.IAI

IF (FL (I, 1).NE. I) GO TO 3599

IF(FL $(I+1, J)$.NE, I) GO TO 3500

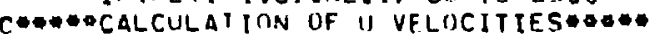

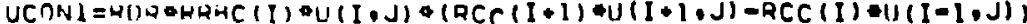

TEY) $=.5 *(V(I+1, J) \bullet V(I, J))$

$E P S=A L P \$ A \cap S I G N(1,1), T E M 1) \bullet H T Z$ TEMI

UCONI $=I E M I *((F P S+n, 5) \cup U(I, J)-(E P S-0,5) * U(I, J * 1))$

TEMI $=.5 *(V(I+1, J-1)+V(I, J=1))$

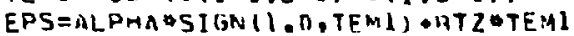

$U C O N H=T E M I *((E P S * 0.5) \otimes U(I, . I-1)-(E P S-0.5) * U(I, J))$

NCE $I S=H U L B(U C O N T-U C U N H)$

UPRF $\triangle=K U Q \otimes(P(I+1, J)-P(I, J))$

UUIF $I=R L I *(11(I, j+1)-3,(1)+1)(I, J)+U(I, J-1))$

UDIF $C=R(1, /((V(I+), J)-V(I, J))-(V(I * I, J-I)-V(I, J-I))$

UT $(I, J)=11(1, J)=0 I 0(U C O N)+!$ ICON? +UPRES-NU $(U D I F I-U D I F L)$ )

3500 IF (FL (I.,1*1). NE. 1) GO TO 3\$99

C****CALCULAIION OF $V$ VEL OCITIES*a***

IEMI $=0.5 *\{U(1, J \cdot 1)+11(1, J\})$

EPS $=A L P H A O S I G N(1.0, T F M L)+B T H=T E M I$

VCONM=RHR (I)*TEMI* ( (FPS*0.5)*V(I.J)-(EPS-0.5)*V(I*I*J))

$T E * 11=.5 *(U(1-1, J * 1) \cdot U(I-1, J))$

EPS = ALDHA $+S I G N(1,0$, IEMI) $\rightarrow$ HTHOTEMI

$V C O N L=R H C(I-1) \otimes T E M I *((F, P S+0, O) * V(I-1, J)-(E P S-0,5) \div V(I, J))$

VCOAJ I =RUHAHLCC (I) (VCONR-VCONL)

VCONL $=R U / O V(1, J):(V(I, J+1)-V(I, J-1))$

VPRE $>=N(1):(P(I, J+I)-D(I, J))$

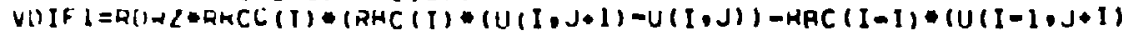

$1-(I(I-\cdot) J U)$

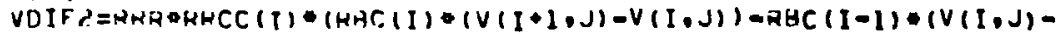

IV $Y(I-1,7))$

VBOUY $=(U, h Q(T(I, J)[1) T(I, J))-T B A K(J))$

$V T(I, J)=V(I, J)-1) T \bullet(V C O N I \bullet V C O N Z+V P R E S+N U \bullet(V D I F I-V D I F ?) \bullet B E T A \bullet G Z *$

| vanuYl

3648 CONT INUE

3699 CONTINIIE.

DO $3750 \quad J=2 . J H$

UO $3749 \quad I=2,14 i$

IF (FL $(I, J)$.NE 1$)$ (GO TO 3750

IF $(F L(I+1, J) \cdot E \omega, I) U(I, J)=(I T(I, J)$

IF $(F L(I, J+1), E Q, 1) \vee V(I, J)=V T(I, J)$

C*OPRESSUHE-VELOCITY ITERATION SECTIUN*⿻**

3749 CONT INUE
CIRCN 513

CIRCO $\quad 514$

CIRCO 515

CIRCO 516

CIRCO 517

CIRCO $51 \mathrm{H}$

CIRCO 510

CIHCO 520

CIRCO 521

CIACO 522

CIRCO 523

CIRCO 524

CIRCO 525

CIRCO 526

CIRCO 527

CIRCN 5 ?

CIRCO 524

CIRCO 530

CIRCO 531

CIRCO 532

CIRCO 533

CIACD 534

CIRCO 535

CIRCN 536

CIRCO 531

CIRCD $5.3 \mathrm{H}$

CIRCO 539

CIRCO 5411

CIRCO 541

CIRCO 542

CIRCO 543

CIRCO $\quad 544$

CIRCO 545

CIACn 546

CIRCO 547

CIRCO 548

CIRCO 549

FIRCO 550

CIRCO

rIRCO 552

CIRCO 54J

r.IRCO 554

CIRCO 555

CIRCO 556

CIRCO 557

CIRCO 54H

CIRCO 559

CIRCO 500

CIPCO 56I

CIRCO 562

CIRCO 563

C.IRCO 564

CIRCO 565

IIRCO 566

CIRCO $\quad 567$ 


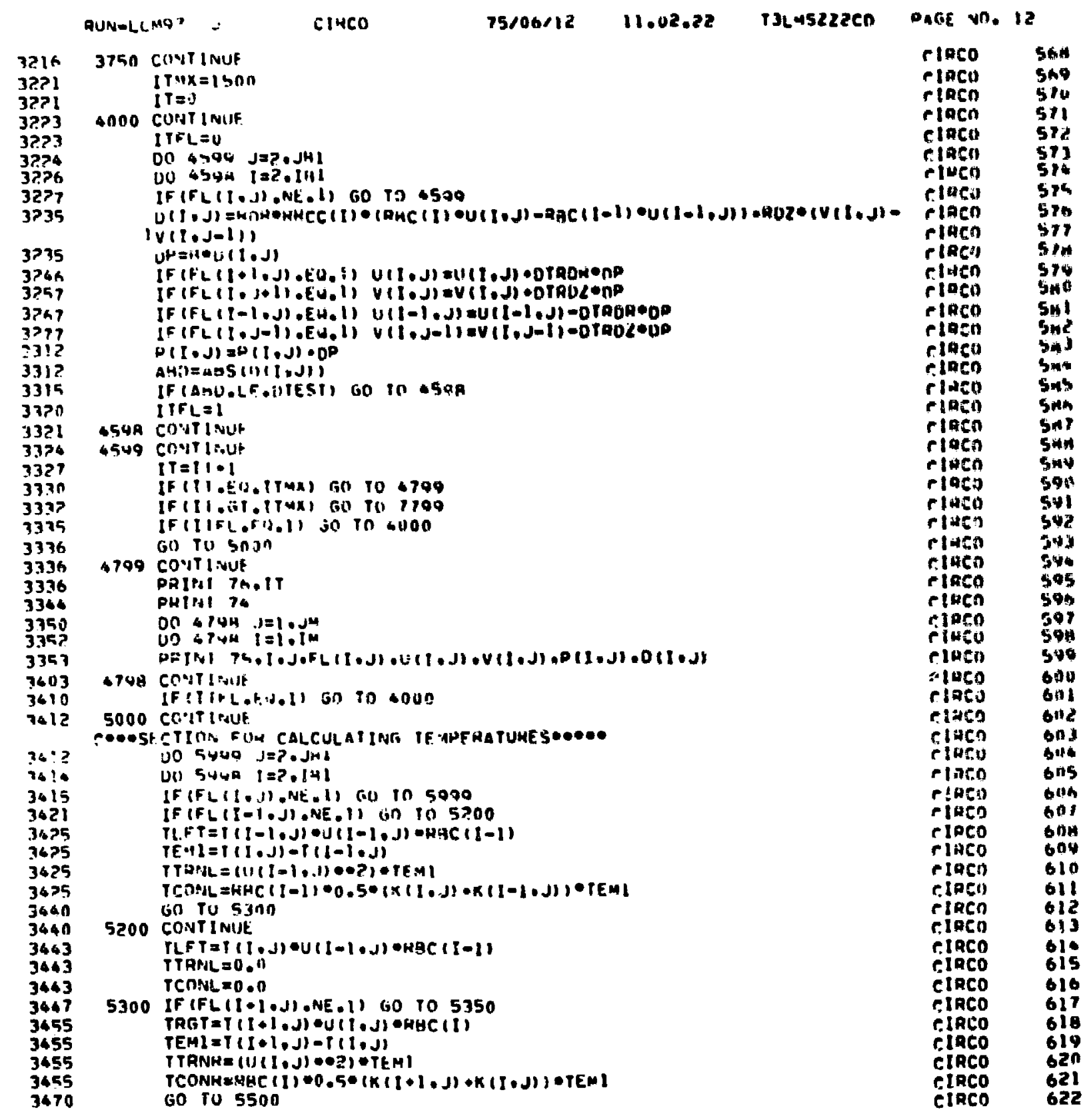




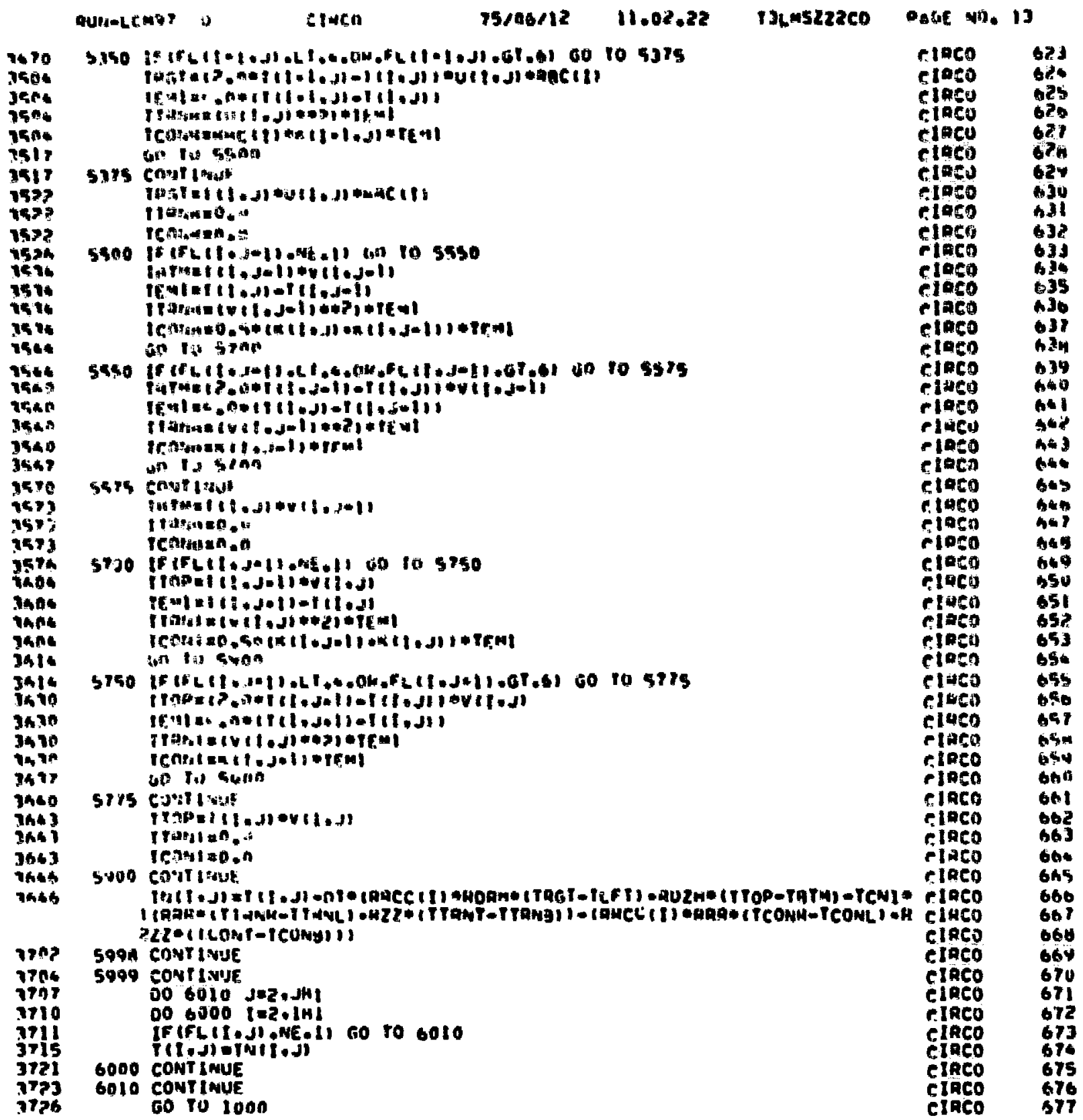




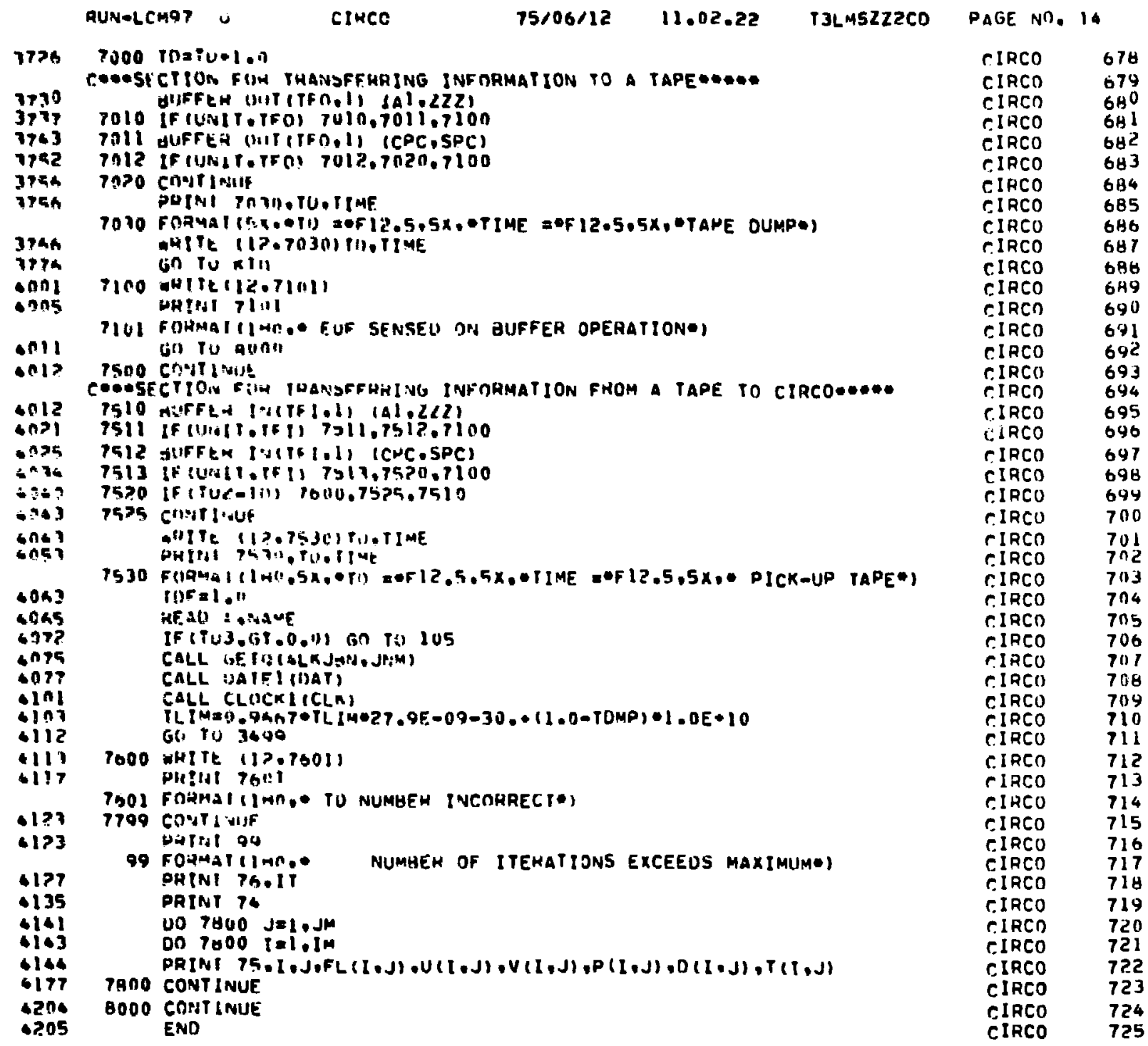




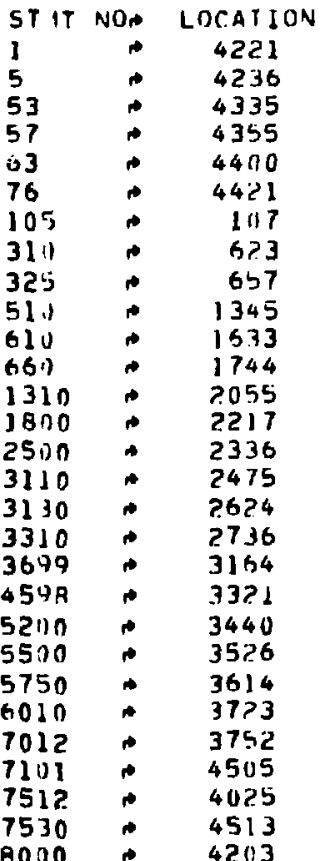

GLIOCK NAMES ANL, LENGTHS

$$
A 2
$$

$$
76106
$$

VAHIARLE ASSIGIVMENTS

\begin{tabular}{|c|c|c|}
\hline 38 & $\infty R$ & 4553 \\
\hline $\begin{array}{l}42 \\
16\end{array}$ & $\mapsto \rightarrow$ & $\begin{array}{r}65 n 4 C 01 \\
415144 C 01\end{array}$ \\
\hline $\begin{array}{l}8 \\
\text { BTL }\end{array}$ & $\begin{array}{l}\oplus R \\
\oplus R\end{array}$ & $\begin{array}{l}74715 \mathrm{COl} \\
747 \mathrm{VCO}\end{array}$ \\
\hline $\begin{array}{l}\text { CPC } \\
\text { DAF } \\
\text { DR } \\
\text { DTHOR } \\
\text { EMG }\end{array}$ & $\begin{array}{l}\leftrightarrow R \\
\rightarrow R \\
\rightarrow R \\
\rightarrow R \\
R A\end{array}$ & $\begin{array}{r}\text { OCO2 } \\
74723 \mathrm{COI} \\
74546 \mathrm{COl} \\
74705 \mathrm{COI} \\
74712 \mathrm{COl}\end{array}$ \\
\hline $\begin{array}{l}\text { FCI } \\
\text { IA } \\
\text { IFHC } \\
\text { INIIM } \\
\text { IAN } \\
\text { IIS }\end{array}$ & $\begin{array}{l}0 I \\
0 I \\
0 I \\
0 I \\
0 I \\
0 I\end{array}$ & $\begin{array}{l}74714 \mathrm{COl} \\
74743 \mathrm{CO} \\
75563 \mathrm{CO} \\
74743 \mathrm{COl} \\
74752 \mathrm{CO} \\
7475 \mathrm{COO}\end{array}$ \\
\hline $\begin{array}{l}\text { J } \\
J\end{array}$ & ol & $\begin{array}{l}4562 \\
4563\end{array}$ \\
\hline
\end{tabular}
NAIE $\rightarrow$ LOCATION
STMT NON LOCATIUN

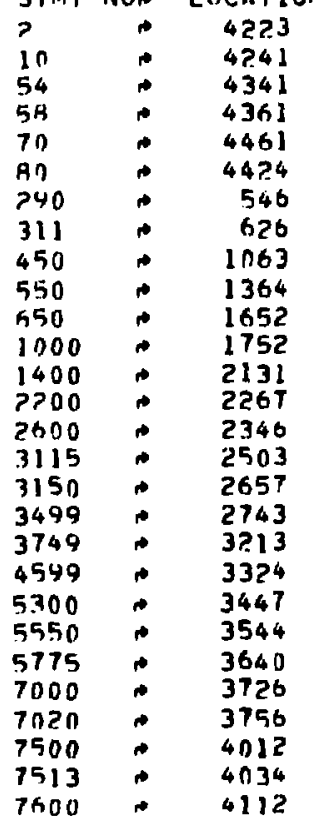

\begin{tabular}{|c|c|c|}
\hline NAME & * & _OCATIUN \\
\hline ALPHA & $\oplus H$ & $7457 \mathrm{BCO}$ \\
\hline $\begin{array}{l}43 \\
A 7\end{array}$ & H & $\begin{array}{l}15350 \mathrm{CO} 1 \\
50270 \mathrm{CO} 1\end{array}$ \\
\hline $\begin{array}{l}\text { HE TA } \\
\text { CEP }\end{array}$ & $\rightarrow H$ & $\begin{array}{l}74574 \mathrm{CO} 1 \\
74 \mathrm{GnZCO1}\end{array}$ \\
\hline $\begin{array}{l}\text { CPL } \\
\text { DCON }\end{array}$ & $\begin{array}{l}\oplus R \\
* R\end{array}$ & $\begin{array}{l}74566 C 01 \\
7471 \mathrm{CCO}\end{array}$ \\
\hline $\begin{array}{l}\text { DT } \\
\text { DTHDL } \\
\text { EPS }\end{array}$ & ${ }_{\rightarrow P}$ & $\begin{array}{c}74550 \mathrm{CO} 1 \\
74706 \mathrm{CO} \\
4555\end{array}$ \\
\hline I IR & +1 & $\begin{array}{r}0 \mathrm{CO} 1 \\
74630 \mathrm{CO} 1 \\
4557\end{array}$ \\
\hline $\begin{array}{l}\text { II } \\
\text { I } \\
\text { IT } \\
\text { I } 2 \mathrm{HC}\end{array}$ & I & $\begin{array}{r}50 \mathrm{CO2} \\
74764 \mathrm{CO} \\
75 \mathrm{C}_{3} \mathrm{COD}\end{array}$ \\
\hline JAR & -I & $74631 \mathrm{CO1}$ \\
\hline$J M$ & & \\
\hline
\end{tabular}

SPCLON * 265

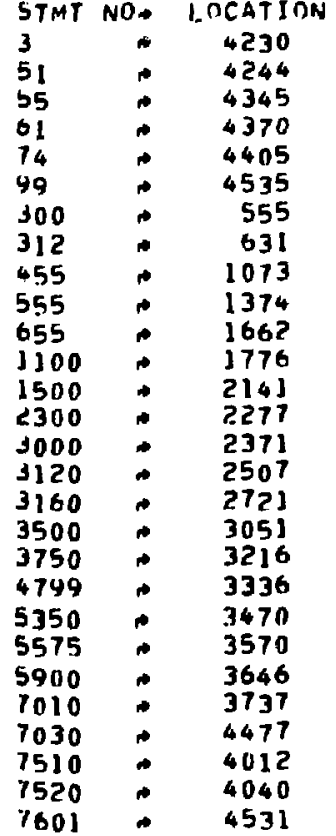

STMT NON

\begin{tabular}{|c|c|c|}
\hline NAME & $\omega$ & LOCATSOIN \\
\hline 10 & $\mathbf{H H}$ & $74424 \mathrm{COI}$ \\
\hline $\begin{array}{l}15 \\
49\end{array}$ & $\omega H$ & $32720 \mathrm{cn} 1$ \\
\hline ATH & $\mathrm{HH}$ & $74671 \mathrm{CO}$ \\
\hline CNPLI & Ah & Thoubca! \\
\hline $\begin{array}{l}\text { D } \\
\text { np }\end{array}$ & $\stackrel{H}{H}$ & $\begin{array}{l}6564 n c, 01 \\
+554\end{array}$ \\
\hline RTEST & AH & T4TITCOS \\
\hline & $\begin{array}{l}\infty k \\
01\end{array}$ & $\begin{array}{l}7+547 \mathrm{Col} \\
7+71 \mathrm{sCOl}\end{array}$ \\
\hline I & 01 & $\begin{array}{c}4550 \\
74755001\end{array}$ \\
\hline 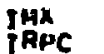 & 01 & $\begin{array}{l}4560 \\
75563 \mathrm{CO}\end{array}$ \\
\hline ITMx & 1 & $74765 \mathrm{col}$ \\
\hline $\begin{array}{l}\text { IzTC } \\
\text { JeNT }\end{array}$ & $\begin{array}{l}-1 \\
01\end{array}$ & $\begin{array}{l}75757 \mathrm{Col} \\
74750 \mathrm{Col}\end{array}$ \\
\hline JNH & +1 & $74703 C_{E S}$ \\
\hline
\end{tabular}

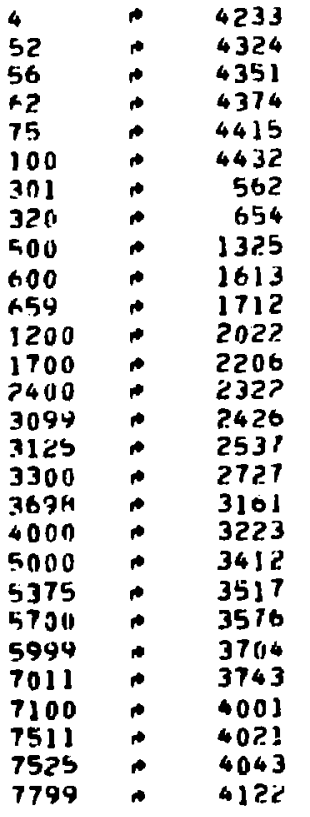




\subsection{4 .22}

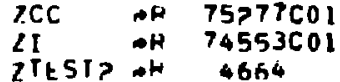

SECOND $\rightarrow R$

NATE I PR

CONTUR $\cap H$

EXTERNAL ASSIGNMENTS

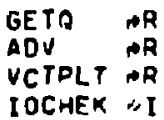

START OF
TEMPOHARIES

4544

LPH
M2
NCP
NN
NPL
NPUT
NWP

NGP

H

HHC

HDKD

KIIH

MHCC

MHC

MTFST

$M 2 \angle H$

ICN

I $\mathrm{CH}$

ICONH

ICONA

Tor

IfI

ILFT

IPI

IWL

ITL

UCON2

UP I

VCONL

VEIPL

VEI

APUT

$\angle C 1$

$\angle 22$

T 3L45CZPCD

$4635 r . n 1$

rotonen

4573

74633r.n!

746.30r.n

$74634 \mathrm{C}, 0$

41504501

7507780

4577

$4673 \mathrm{Cn}$

$75151 \mathrm{Col}$

t4tonco

$46 n 3$

$74676 \mathrm{rol}$

$7457 ! r . n !$

$76424 r . n 1$

460 !rn

4h1?

4020

462 ?

4626

214 C.n?

4631

$14557 \mathrm{Cn}$ !

4335

(64)

inco?

$24134 \mathrm{Col}$

4647

74603col

20acio?

20260 ?
$7456 \mathrm{Cal}^{2}$

4660

1662

UUTPYC $\triangle P$

ClOCKI $\rightarrow$ A

LINCNT $\rightarrow 1$

END

INUTAECTS

4551
Page no. is

1. WH 1 T4636CnI

M. AI 45I

werc of $7675 / C n 1$

HOC Al 74773COI

MPL ol 7476ICOI

HTIM of 4576

NHAI of T476LCOI

PIN HA THSBCOI

ac

WD

a 450

HN 4575

WHL OH 74703CnI

unzit an 7467aCDI

WHA of THGh4COI

USII $\$$ H $\$ 601$

WrFCT $O A$ THIlicol

a722 $\mathrm{H}$ Th T67icni

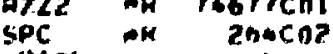

THASt $\mathrm{OH}$ GGAS

ICIII THTPoCII

leurl $A \mathrm{H}$ 4b/3

Tont on T4Bnical

IfIS AH Ta5obenI

Trit AN THSobCaI

ILIM OH 462t

TPL AL $2 z \circ C 0 ?$

TTKKL AN HEJZ

T1 on TA5SSCAI

ICUNH $\mathrm{AN}$ 46.16

IIDIF, OA 464?

IIPO $O A$ Z4UCO?

VROUY $\mathrm{H} 4645$

YCONH $\mathrm{NH} 4650$

YDIF 1 at

vIn कH TAsticol

YPO A $252 C 0$ ?

ZAC OA TSAzICOI

TCz की 1661

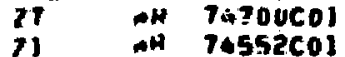

INPUIC -1

ACGUE'H $\triangle$

MIIFFEO AH

OANTAY

JNuSE D CUMP ILEK SPACE 
SHAHIMTI'A VCTRL! VCTPLT

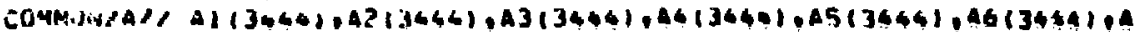

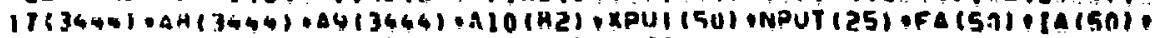

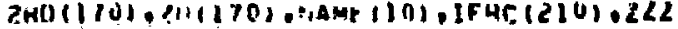
cotmundsor. CDM4

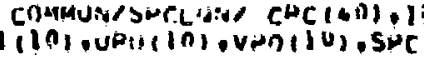
cony C.0\%4

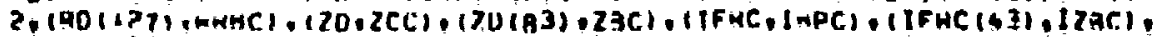
3IIFRC (I251. 1<TC)

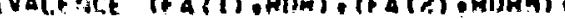

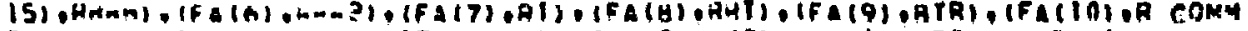

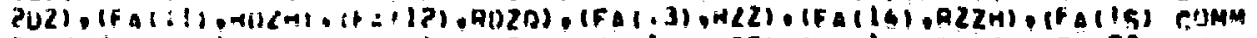

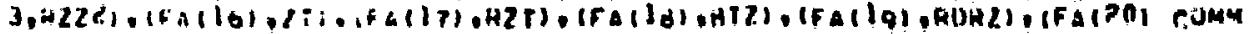

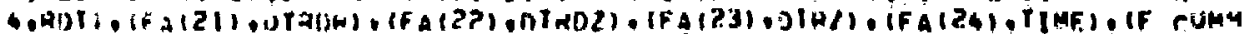

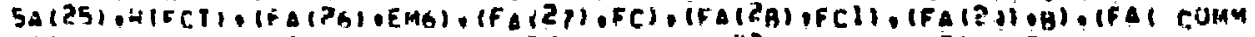

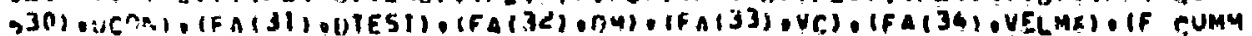

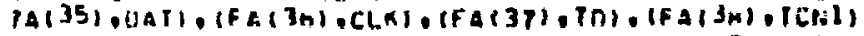

ron'

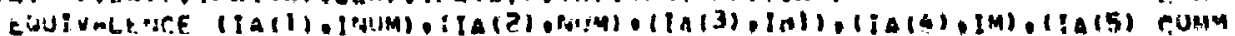

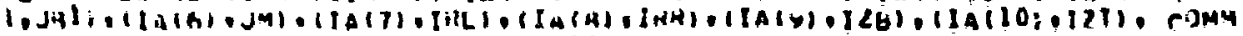

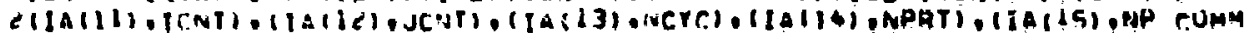

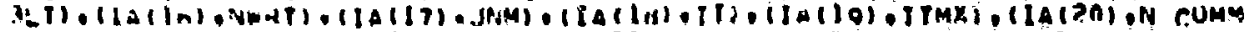

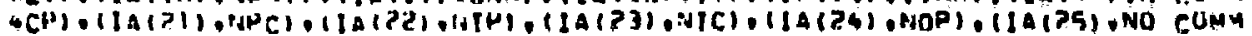
SCl

rising

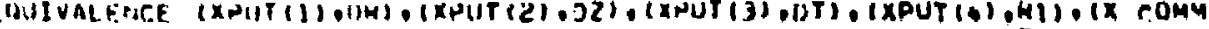

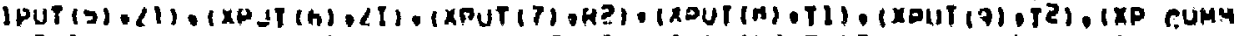

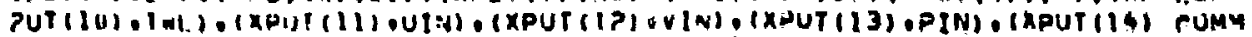

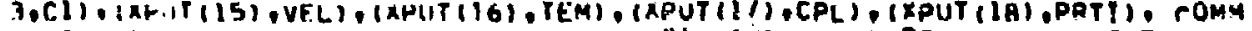

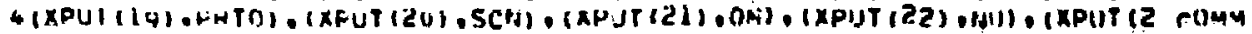

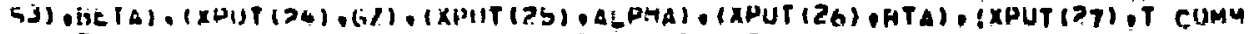
GFACT), (X2:1T(2A), ICN) $(X P 1 T(29), C E P),(X P U T(30), V C T P L),(X P U T(3), V M)$ COMY

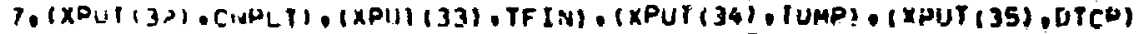

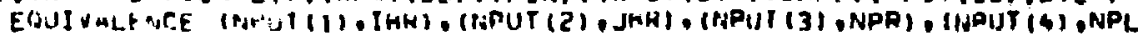

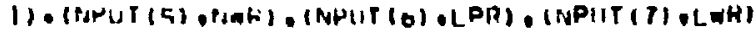

INTFUEN IFI, TFU

INIEUEN FL,FCOFCI

AEAL INC.X,NU

rUMY

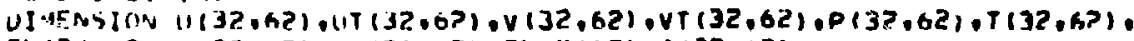

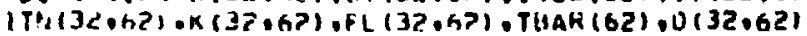

1 FORMAI (INO, IHX, IUAG,1X,AID, 2(IX,AA))

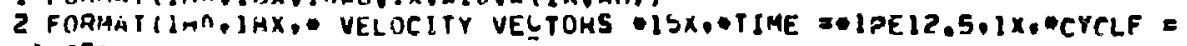
$1 \cdot[5]$

3 FORMAT (1HD. IAX.* CONSTANT SCALING FACTOR -15X,EU HORIZONTAL V VEAT IICAL

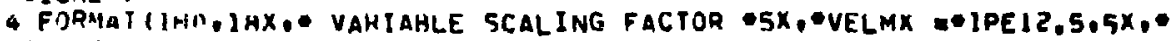
IU HOHILUNTAL V VERTICALOI $N P L O T=B$

110 CONTINUE NPLOI $=$ NPLOT 1

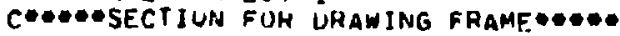
CALL ADV (1) ICNM $=$ ICNT-I

rOMY

romis

cOMY

romy

rumy

roma

comy

romy VCTOLT VCTPLT VCTPLI VCTPLI VCTPLI VCTPLI VCTPL VITPLT VCTDLT VCTPLT VCTPLT VCTPLT VCTPLT VCTPLT 
PAUF. NO.?

JCNHa JCNi-1

J) IsU L $=1$, ICNA

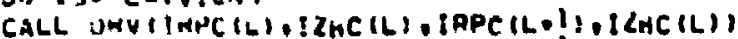

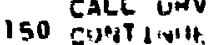

Uo $106 L=1, J C N A$

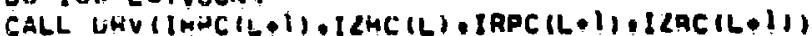

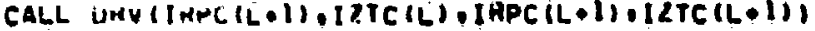

160 COTI INUS

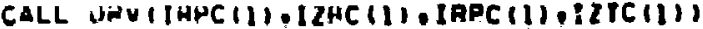

CALL UNV IIMPC (ICNT) IZHCIJRTT) IAPC (ICNTI I I TC (JCNTI)

CALL L IAC'TI (5H) GD TU $(1+1$, PYO , NPLUT

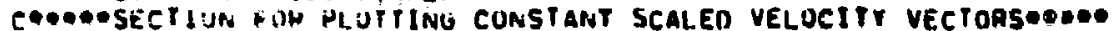

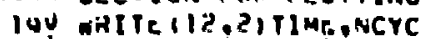

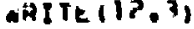

-HITr IIZ, IINAME, JNM, DA I, CLK

vo $21: j=2, J a 1$

un zud $|\geq 2|+,\mid$

IF (FLII,$H$.NE I) GO TO 2 I0

UVECENCL (I) UCE $0.5 \circ(U(1,)+.U(1-1, J)$

VVEC $=\langle C(1,) \cdot V(\theta, 5 \bullet(V(I, J) \bullet V(1, J-1)$

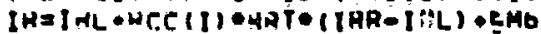

$I Z=I \angle A+Z C C(J) \bullet H / T \bullet(I Z T-I Z I I)+E M O$

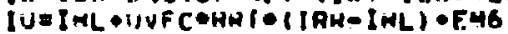

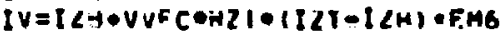

500 continut

210 COHTINAIF.

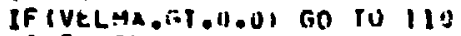
iso Tu bל:'

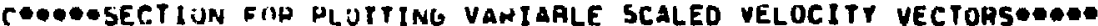

zQ0 AFITE $(1 ?, P) I I M E$. VCYC

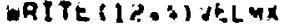

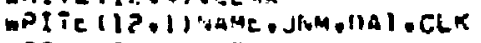

VSC $=0.5 *$ InH $\bullet U Z$ I IVELAX

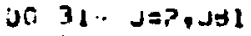

Do $300 \quad I=5,|4|$

iF (FL II . I) ,NE. I) ro TO 310

UVEC $=M C C(1) \cdot U S C \cdot 0.5 \bullet(U(I, J) \bullet(1)(I-1, J))$

$V V E C=\angle C C(J) \bullet V S C \bullet 0.5 \bullet(V(I, J) \bullet V(I, J-11)$

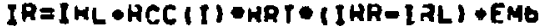

$I Z=I \angle H+\angle C C(J) \bullet H Z T \cdot I I Z T-I Z H) \cdot E M 6$

$I U=I N L \bullet U V E C \oplus H R T \cdot(I H H=[H L)+E M 6$

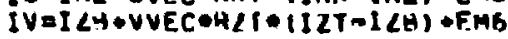

CALL UHV (IR,I $Z, I U, I V)$

300 CONT IN!IE.

710 CONTIRUF

350 CONTINUE:

RETUNN

END
VCTPLT

VCTPLI

VCTPLT

NCTPL.T

VCTOLT

VCTCLT

veTPit

VETPLT

VCTHLT

VCTPLT

VCTPLT

VCTPLT

VCTPLT

VCTPLit

VCTPLT

VETOLT

VCTPLT

VCTPLT

VCTPLT

VCTD.I

nCTPLT

VCTOLT

VCTPL.T

vCTPLT

VCTPLF

vETPL

vCTFLI

VCTPLT

vCTPL

VCTPE

VCTOLT

VCTPLI

VCTPL

VCTPLI

VCTPLi

yCTOLF

VCTPLT

VCTPLT

vCTPLT

VCTPLT

VCTPLT

VCTPLT

VCTPL T

VCTPLT

VCTPLI

VCTPLT

VCTPLT

VCTPLT

VCTPLT

VCTPLT

vETPLT
10

$1 y$

21

22

$+3$

24

20

?7

28

24

30)

31

32

j4

34

36

37

3H

34

411

41

48

43 
RINALCM97 0 VCTPLI T5/06/12 11.02 .22 TJLMSZ2ZCD PAGE ND. 3

427

STATEMENT ASSIITMMENIS ST:AT NO* LOCAIION

$110+337$

$310 \div 331$

BLUCK NAMES ANII LENGTHS AL $\rightarrow$ ThI 66

VAYTABLE ASSIGNHENT MAIE - LOCAIION

$\begin{array}{lcc}\text { STMT NO* LOCATIUN } \\ 2 & 344 \\ 190 & 62 \\ 350 & + & 334\end{array}$

SPCLON $\rightarrow$ PGS

naME - LOCATIUN

ALPHA $\rightarrow$ H 74576601

43 OP $15350 C O$

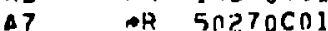

HETA $\rightarrow R$ 745/4COI

CEO $\quad \mathrm{H} \quad 746 \mathrm{G}$ OCOI

$C P L \quad \rightarrow R \quad 745 n 6 \mathrm{COI}$

UCUN $A R \quad 74716 C 01$

TTCP R ?4610COI

DTHz $74707 C 01$

FC $\quad$ AI $74713 \mathrm{COI}$

I $\rightarrow I \quad 410$

IC.JM $\quad$ I 411

IRPC $1755 \wedge 3 \mathrm{CO}$

IU $\rightarrow$ I 413

IZHC $\rightarrow$ I $75635 \mathrm{COI}$

J3. $174631 \mathrm{COI}$

JM il $74750 \mathrm{COI}$

LPis ol $74635 \mathrm{COl}$

NCYC $174747 \mathrm{CO}$

NOP $\rightarrow 17472 \mathrm{CO}$

NPLT I $747 \mathrm{MCO}$

NJ क $74573 C 01$

NM 74572001

HRTI OA 74567COI

HO $750>5 \mathrm{CO}$

HOHZ $A$ A 74713COI

KDTD AH 74674COI

WRHH $P R \quad 74655 C O 1$

HTFCT $\rightarrow \mathrm{H} 74711 \mathrm{CO}$

HZLZ $P$ R $74677 C 01$

$T \quad A R \quad 50270 \mathrm{COI}$

TD AP 74725COI

TFI $\rightarrow 1422$

TN $\quad$ H $32720 C 01$

un

UPI $A R$ 170CO?
A $\rightarrow B \quad 0 C O 1$

Q4 $\mathrm{AH} 24134 \mathrm{COI}$

$A 4 \quad \mathrm{R} \quad 57054 \mathrm{COI}$

ATA $A R$ 74577CO

CLK AR 74724COI

OM OH 74720COI

DIEST $\rightarrow$ P 74717COI

D) $\quad 74547 \mathrm{COl}$

FCl I $74714 C 01$

IA OI $74743 \mathrm{COI}$

ICNT OI $74755 C 01$
IOC OH

IHA HI 74752001

IV I 414

I.T I $74754 \mathrm{CO}$

JHI I $74747 \mathrm{COI}$

JNM I 74763001

LWR 174630001

NIC OI $74771 C 01$

NPR $+74532 \mathrm{CO}$

NIIM I $74744 \mathrm{CDI}$

DPC NH 120CO?

PHTO $\rightarrow H$ 74570COI

RDH $74661 \mathrm{CO}$

RDT $447470 \mathrm{COl}$

HHBC $\mathrm{AH} 75223 \mathrm{COI}$

H2T $A \mathrm{H} 74701 \mathrm{CO}$

$\mathrm{HI} \rightarrow \mathrm{R} \quad \mathrm{T4551 \textrm {CO }}$

THAK $P$ H $74424 \mathrm{CO}$

TUMP $\rightarrow H$ 74607COI

TPI $\rightarrow R \quad 214 \mathrm{COZ}$

$T 2 \quad+R \quad 74556 \mathrm{CO}$

UC $P R$ T4T21CO

VIN $P$ R 7561001

VIN $O R$ T456ICOI

ZHC $\quad$ AR 754?ICOI
C. $\mathrm{OH} 74563 \mathrm{CO}$

NPC I $74767 \mathrm{COI}$

RAH2 $\rightarrow$ TA T46G6COI

TFIN AR 74606COI

VELMX AR $24134 \mathrm{CO}$

VELMX AR 74722COI

$\begin{array}{llr}\text { VPI) } & \rightarrow R & 252 \mathrm{COZ} \\ X P U T & \rightarrow R \quad 74546 \mathrm{CO} 1\end{array}$

$\begin{array}{lc}\text { STMT NON LOCATION } \\ 3 \\ 210 & 354 \\ 210 & 200\end{array}$

STMT NO LOCATION $290 * 205$

\begin{tabular}{|c|c|c|}
\hline VAME & $\oplus$ & DCATION \\
\hline A 10 & $A B$ & $74424[.01$ \\
\hline$A 5$ & $\rightarrow R$ & $32720 \mathrm{COI}$ \\
\hline$A \varphi$ & $A$ & $65640 C 01$ \\
\hline $87 \mathrm{H}$ & $\cap R$ & 14671001 \\
\hline CNPLT & $A R$ & $74605 \mathrm{Cn} 1$ \\
\hline u & $A R$ & $6564 \mathrm{nC01}$ \\
\hline OF & $A$ & $74546 r .0 ?$ \\
\hline OTHOH & $\oplus R$ & $74705 r .01$ \\
\hline EMG & $\rightarrow R$ & 74712001 \\
\hline$F L$ & +1 & orn? \\
\hline I RH & - I & $74630 \mathrm{COI}$ \\
\hline $\begin{array}{l}l_{\text {FHC }} \\
\text { lk }\end{array}$ & +1 & $\begin{array}{c}75563001 \\
412\end{array}$ \\
\hline 17 & +1 & $74764 \mathrm{COI}$ \\
\hline 12 & -1 & 415 \\
\hline $\begin{array}{l}I \angle T C \\
\text { JCNA }\end{array}$ & $\rightarrow I$ & $\begin{array}{c}75757 r n 1 \\
417\end{array}$ \\
\hline$k$ & P & $5705+C .01$ \\
\hline NAME & +1 & $75551 \mathrm{COI}$ \\
\hline N]P & - I & $74770 \mathrm{CnI}$ \\
\hline NPL. & +1 & 74633501 \\
\hline NPHT & +1 & 74760r:n! \\
\hline NWR & -I & $74634 C .01$ \\
\hline $\boldsymbol{P}$ & $\rightarrow P$ & $415 n 4 r .01$ \\
\hline $\begin{array}{l}\text { HHC } \\
\text { HDHH }\end{array}$ & $\stackrel{* R}{* R}$ & $\begin{array}{l}75077 \mathrm{COA} \\
746 \mathrm{~B}>\mathrm{Cn} 1\end{array}$ \\
\hline $\mathrm{HDL}$ & $\leftrightarrow A$ & 14672001 \\
\hline HRCC & $\rightarrow R$ & $75151 \mathrm{col}$ \\
\hline HRT & $A R$ & $766700 \mathrm{col}$ \\
\hline HZZ & AR & $74675 r n 1$ \\
\hline $\begin{array}{l}\mathrm{H}_{2} \\
T E N\end{array}$ & AR & $\begin{array}{l}74554 \mathrm{CD} 1 \\
746 \mathrm{ClON}^{2}\end{array}$ \\
\hline TEM & $\rightarrow R$ & $74565 \mathrm{COl}$ \\
\hline IFO & $\rightarrow 1$ & 423 \\
\hline IPL & H & $2 \overline{2} 6 \mathrm{Cn} 2$ \\
\hline$u$ & $\sim R$ & $6564 \mathrm{C}_{01}$ \\
\hline $\begin{array}{l}\text { UT } \\
\text { VCTPL }\end{array}$ & $\leftrightarrow A$ & $\begin{array}{l}15350 \mathrm{CO} 1 \\
74603 \mathrm{CO} 1\end{array}$ \\
\hline VM & $A R$ & $74604 \mathrm{CO} 1$ \\
\hline $\begin{array}{l}V_{1} \\
\text { LCC }\end{array}$ & $\stackrel{P R}{A R}$ & $\begin{array}{l}32720 \mathrm{CO} \\
75277 \mathrm{COl}\end{array}$ \\
\hline
\end{tabular}

\begin{tabular}{|c|c|c|}
\hline AME & 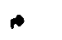 & OCAI I ON \\
\hline A? & $A H$ & hénocol \\
\hline$A 6$ & 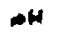 & $-15 n+C 01$ \\
\hline A & $B N$ & $74715 \mathrm{Cn} 1$ \\
\hline $\begin{array}{l}\operatorname{arl} 2 \\
\operatorname{coc} 2\end{array}$ & As & $\begin{array}{r}74702 C 01 \\
\text { (1C0? }\end{array}$ \\
\hline $\begin{array}{l}\text { CPC } \\
\text { UAT }\end{array}$ & $\begin{array}{l}A K \\
-H\end{array}$ & $\begin{array}{r}\text { rCO? } \\
7.72 \mathrm{SCO} 01\end{array}$ \\
\hline זח & $\Delta \mathbf{M}$ & 745 JuCn1 \\
\hline $\begin{array}{l}\text { IITULL } \\
\text { f }\end{array}$ & $\stackrel{A H}{A H}$ & $\begin{array}{l}74706 C 01_{1} \\
74661 \mathrm{Cn}\end{array}$ \\
\hline $\begin{array}{l}n, 2 \\
{[B]}\end{array}$ & N & $\begin{array}{l}74575 \mathrm{CO} 1 \\
74745 \mathrm{COI}\end{array}$ \\
\hline $\begin{array}{l}I M \\
I R L \\
I_{I M X} \\
I Z H\end{array}$ & $\begin{array}{l}01 \\
-1 \\
01 \\
01\end{array}$ & $\begin{array}{l}74746 C 01 \\
74753 \mathrm{COI} \\
74765 \mathrm{CO}) \\
74753 \mathrm{CO} 1\end{array}$ \\
\hline${ }_{J}^{J} \mathrm{CN} T$ & -1 & $\begin{array}{c}410 \\
747565.01\end{array}$ \\
\hline 1 & +1 & 421 \\
\hline $\mathrm{NCP}$ & AI & $747 \mathrm{bbCOl}$ \\
\hline$\triangle O C$ & - I & $74773 \mathrm{COO}$ \\
\hline NPLUT & -1 & 421 \\
\hline $\begin{array}{l}\text { NPUT } \\
\text { NWHT }\end{array}$ & 01 & $\begin{array}{l}74630001 \\
74762 C 01\end{array}$ \\
\hline $\operatorname{VIN}$ & $\infty \mathrm{H}$ & 74562001 \\
\hline $\begin{array}{l}\mathrm{BCC} \\
\text { HDHU }\end{array}$ & $\stackrel{H}{A R}$ & \\
\hline HOZH & $A H$ & $74673 \mathrm{Cn}]$ \\
\hline $\begin{array}{l}\text { HRH } \\
\text { HT }\end{array}$ & $\stackrel{H}{A K}$ & $\begin{array}{l}7466+\mathrm{Cn} 1 \\
74667 \mathrm{CnI}\end{array}$ \\
\hline$+7: 2 \mathrm{ZH}$ & $A H$ & $7467 \mathrm{bCOI}$ \\
\hline $\begin{array}{l}\text { SCN } \\
\text { TCHI }\end{array}$ & $\begin{array}{l}A H \\
A H\end{array}$ & $\begin{array}{l}76571 \mathrm{CO} \\
74726 \mathrm{CO}\end{array}$ \\
\hline TFAC & $+H$ & $74500 C 01$ \\
\hline TIME & $\Delta$ & 74710601 \\
\hline TWL & $D R$ & $74557 \mathrm{COl}$ \\
\hline UIN & $A A$ & 74560001 \\
\hline $\begin{array}{l}\text { UVEC } \\
\text { VEL }\end{array}$ & $A R$ & 74564001 \\
\hline VPI & AR & $202 \mathrm{CO} 2$ \\
\hline & & \\
\hline
\end{tabular}


VETPLT

$2 T$ $\rightarrow P$

EXTERNAL ASSTGNMENTS

ADV OR

DRV

$\rightarrow R$

CONSIANIS

336
$75 / 06 / 12$

$74700 \mathrm{CO} 1$

TEMPOHARIES

401 $\begin{array}{cc}11.02 .22 & \text { T3LMSZZZCO PAGE NO. } \\ \angle 1 & \text { AR } 74552 C O L\end{array}$

41

LINCNT I

INDIRECTS 407
ACGOEH AR

UNUSEN COMPILER SPACE 
SUARUUTINE CONTUM

CONTUR

COMMUN/AL/ Al(3444),A2(3444),A3(3444),A4(3444),A5(3444),A6(3444), A COMM $17(3444)$, AH (3444),A9(3444), A IU (4L), XPUT (50) ,NPUT (25), FA(SO), IA(50), COMM $2 R O(17(1), 21)(170)$, NAME $(10)$, IFHC $(210), 222$

COMM COMMUN/SPCLUN, CPC $(40), I P C(40), O P C(40)$,UPI $(10), V P I(10)$, TPI $(10), T P L$ COMH $1(10), U P U(10), V P()(1 U), S P C$

COMY

EQUIVALFNCE $(A), F L),(A 2,1),(A 3, U T),(A 4, V),(A 5, V T),(A G, P),(A 7, T),(A, C O M M$

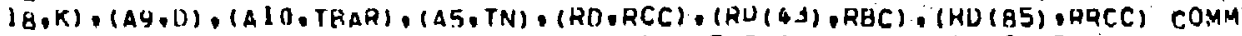
?. (AD ( +27$)$, RREC), $(Z O, 7 C C),(Z O(B), 23 C),($ IFHC,IKPC), (IFRC (43), IZAC), COMM उIIFRC (125), I $\angle T C)$

COMM

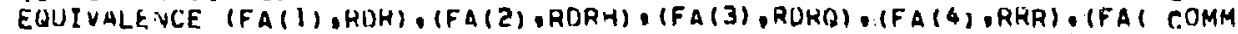

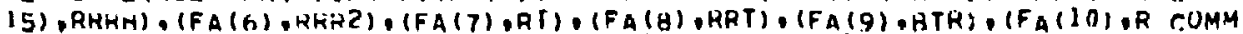
$20 Z),(F A(11), K D Z H),(F A(12), R D Z Q),(F A(13), R Z Z),(F A(14), R Z Z H),(F A(15)$ COMM

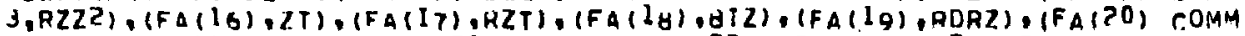
4,ROT) , (FA (Z1), UTHOR), (FA (2?), ПTHOZ), (FA (23), DIRZ), (FA(24),TIME), (F COMM $S A(25), H T F C T),(F A(26), E M G),(F A(27), F C),(F A(28), F C l)$, (FA $(2 Q), Q),(F A($ COMM G 30 ), UCON) , (FA (3) , UTEST), (FA (32),DY), (FA $(33), V C),(F A(34), V E L M X),(F$ COMM $7 A(35), 1) A T),(F A(36), C L K),(F A(37), T D),(F A(3 A), T C N)$ EQUIVALENCF. (IA(I), INUM), (IA (2), NIIM), (IA (3), IB(), (IA $(4),(M),(I A(5)$ COMM

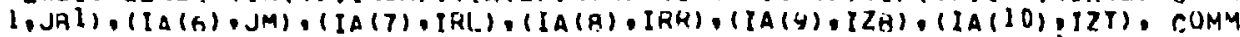
2(IA (II),ICNT), (IA (IZ), JCNT), (IA (13),NCYC), (IA (14),NPRT), (IA I5),NP COMM

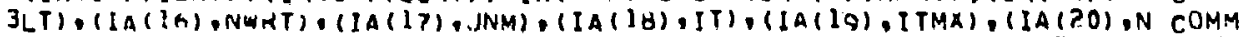
$4 C P),(I A(>), N P C),(I A(22), N I P),(I A(23), N I C),(I A(24), N O P),(I A(25), N O$ COMM SC)

EQUI UALF NCE $(X P U T(1), D H),(X P U T(2), 0 Z),(X P U T(3), 0 T),(X P \cup T(4), R),(X$ IPUT (S),Z1), (XPUT $(6), Z 1),($ XPUT $(7), 8 Z),($ XPUT (O), I),$($ XPUT (9) , TZ), (XP COM4 ZUT (lU), INL), (XPIIT(1), UU(N), (XPUT $(12), V I N),(X P U T(13), P[N),(X P U T(14)$ COMM 3.C1), (XFUT (15),VFL), (XUUT(16), TEH), (XPUT (II),CPL), (XPUT (IB),PRTI), COMM $4(X P U I(19)$, PHTO) , (XPUT $(20), S C N),(X P J T(2)$, OM), (XPUT (2Z) ,NU) , (XPUT (2 COMM 53), BE IA) \& (XPUT (24), G2) , (XPUT (25), ALPHA) , (XPUT (26) , BTA) , (XPUT (27) , T COMM GFACT), (AHUT (2F), TCN ), (XPUT (29), CEP), (XPUT (30),VCTPL), (XPUT (31), VM) COMM 7. (XPUI (32),CNPLI), (XPUT (33). TF IN), (XPUT (34), TUMP), (XPUT (35),DTCP) C.OMM EOUI VALENCF (NPUT (1), IHR), (NPUT (2), JUR), (NPUT (3), NPP), (NPUT (4), NPL COMM 1). (NPUT ( 5$), N$ N , (NPUT (6), LPH), (NPUT (7), LNH) INTEGER IFI,IFO INTEGEH FLOFC,FCl REAL IPC, $K, A: U$ UIMENSIUN U (32,62), UT (32,62), V(32,62), VT (32,62),P(32,62),T(32,6?), ITN $(32,62), K(32,62), F L(32,62), T H A R(62), 0(32,62)$

UIMENSIUN HCC ( $\$ 2), R A C(32)$, RRCC (3Z), RRBC (32), ZCC (62), ZRC (62) OIMENSION IHPC (3Z), IZHC (6Z), IZTC (6?) DIMENSIU, CO(32,6?), CON $(21), R(4), Z(4), H P(2), 2 P(2)$

C*\&SUUROUIINE FOR PLOTIING TEMPERATUHE AND PRESSURE CONTOURS**** NPLOI T 0

150 CONT INUE NPLOI $=N H L O T+1$ GO TU $(200.230 .750)$.NPLOT

$20000210 \mathrm{~J}=1, \mathrm{JM}$ $00 \quad 510 \quad I=1, I M$ $\operatorname{CQ}(I, J)=P(I, J)$

210 CONT I HUE GO TU 250

230 UD $240 \mathrm{~J}=1, \mathrm{JM}$ DO $240 \quad 1=1,1 \mathrm{M}$ $\operatorname{CO}(I, J)=T(I, J)$

COMM

COMM

СОМM

COMM

гомM

гОMM

COMM

COMY

CUNTUR CONTIHA

CONTUH

CONTUR

CONTUH

CONTUR

CONTUK

CONTIJH

CONTUH

CONTUH

CONTUH

contuR

CONTUR

CONTUH 


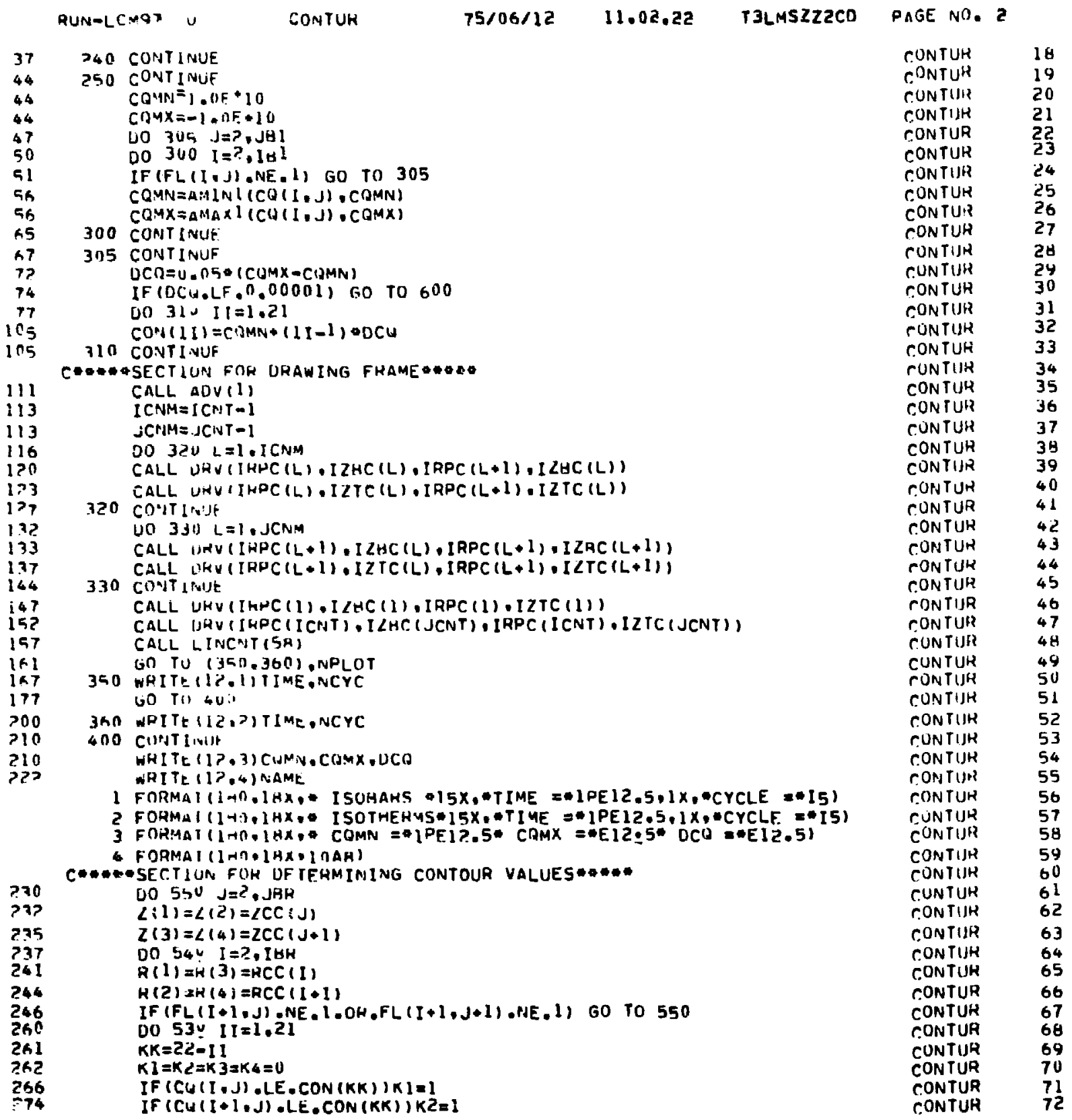




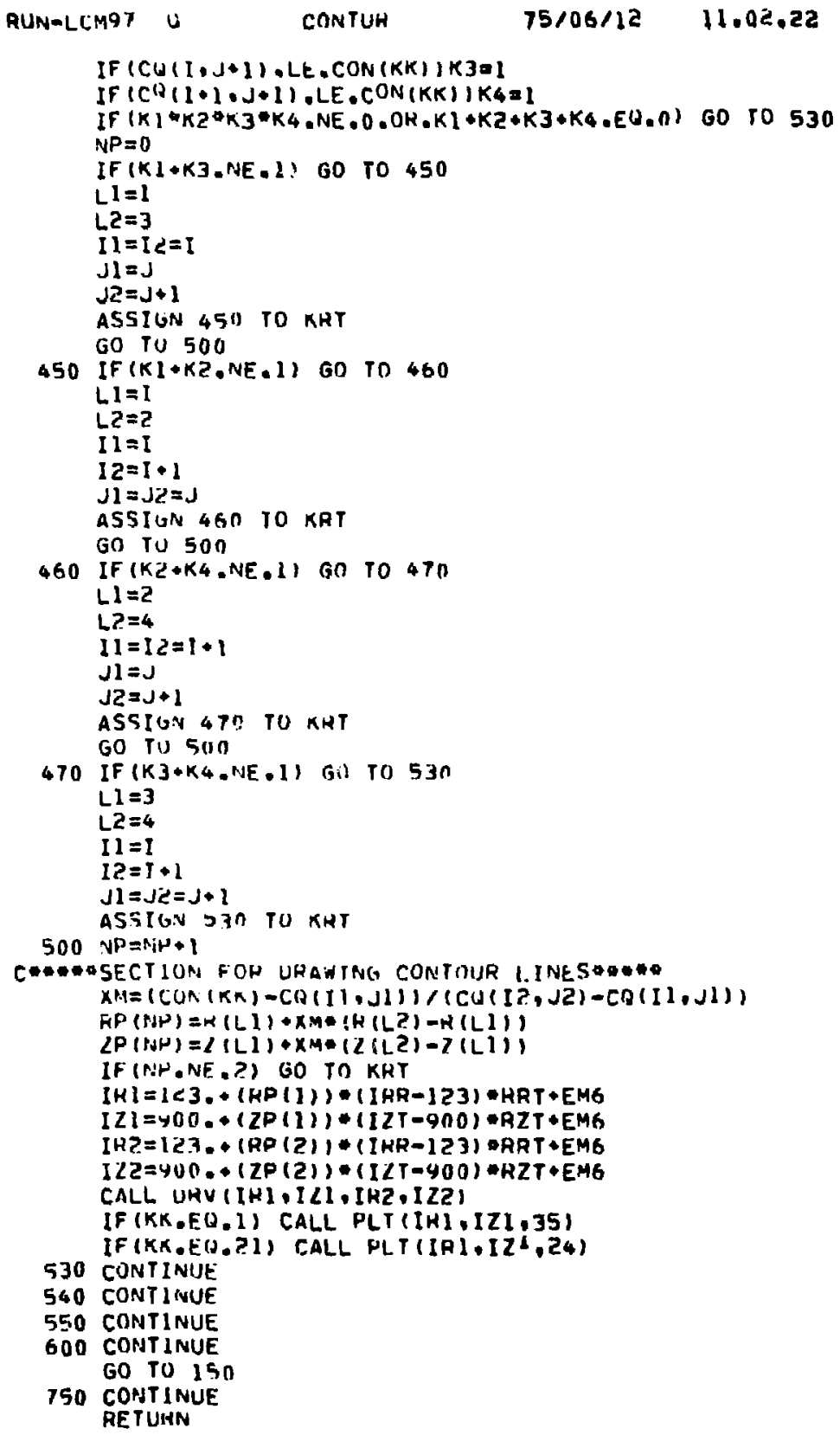

IF (CU (I,J+1), LE, CON $(K K)) K 3=1$

If $\left.\left.\left(C^{\prime}\right)(1+) \cdot J+1\right), L E \cdot C O N(K K)\right) K 4=1$

If $(K) * K 2 * K 3 * K 4 . N E \cdot 0 \cdot 0 K \cdot K) * K 2 * K 3 * K 4 \cdot E O .0)$ GO TO 530 $N P=0$

IF $(K 1+K 3$.NE.1) 60 TO 450

$L 1=1$

L. $2=3$

$I I=I L=I$

$\mathrm{Jl}=\mathrm{J}$

$\sqrt{2}=\mathrm{J}+1$

ASSIGN 451) TO KRT

GO TU 500

$450 I F(K I+K 2$. NE. I) GO TO 460

$L 1=I$

$L 2=2$

$I I=I$

$12=I \cdot 1$

$\mathrm{Jl}=\mathrm{J} 2 \mathrm{I}=\mathrm{J}$

ASSIGN 460 TO KRT

GO TU 500

460 IF (K2 *K4.NE.1) GO TO 470

$L I=2$

$L 2=4$

$11=12=1+1$

$\lambda l=J$

$J 5=J+1$

ASSIUN 47 ? TU KHT

GO TU 500

470 IF $(K 3+K 4$. NE. 1$)$ Gi) TO $53 n$

$$
\mathrm{L} 1=3
$$

$\mathrm{L} 2=4$

Il $=1$

$15=1+1$

$J 1=J i=j+1$

ASTIGN $\supset 30$ TO XHT

$500 \quad N P=R_{i N}+1$

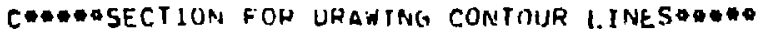

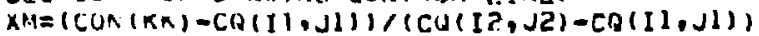

$F P(N P)=R(L L)+X M * ! H(L 2)-K(L 1))$

$\angle P(N A H)=L(L I)+X M=(Z(L Z)-Z(L 1))$

IF (NH.NE, ? ) GO TO KHT

$I H I=1<3 .+(H P(1))-(1 H R-123)=H R T+E M 6$

$I Z l=y 00 *(Z P(1)) *(I Z T-900) * R Z T+E M G$

$I H Z=123 .+(R P(2)) *(I H R-123)$ QRAT *EMG

$I Z Z=400 * \cdot(Z P(2)) *(I Z T-400) * R Z T \cdot E M 6$

CALL UHV (IHI,ILI,IKZ,IZZ)

IF (KK,FO.I) CALL PLT (IH],IZI,35)

IF (KK.E(J.?I) CALL PLT(IPI,IZ, Z4)

530 CONTINUE

540 CONTIINUE

550 CONTINUE

600 CONTINUE

GO TO 150

750 COHTINUE

RETUIN

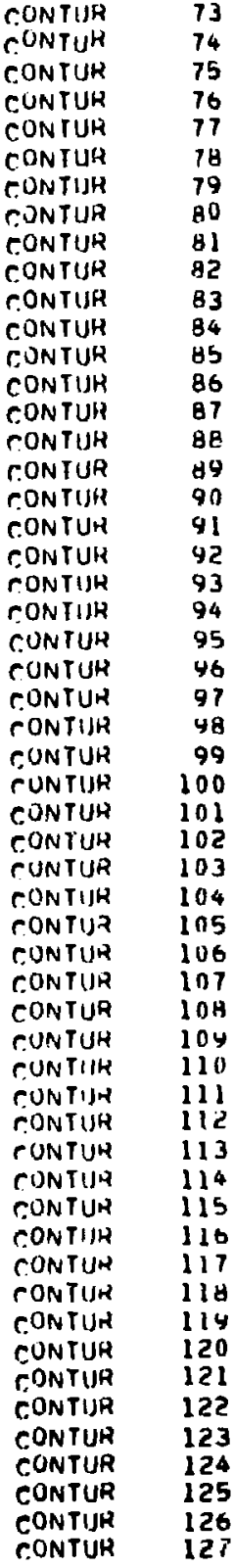


VATIARLE ASSIGNMENTS NA IE $\rightarrow$ LDCAIJON

$\begin{array}{lcc}\text { STMI NO* } & \text { LOCATION } \\ 2 & * & 536 \\ 200 & 13 \\ 350 & * & 167 \\ 460 & * & 353 \\ 550 & * & 511\end{array}$

SPCLON $\rightarrow \quad 265$

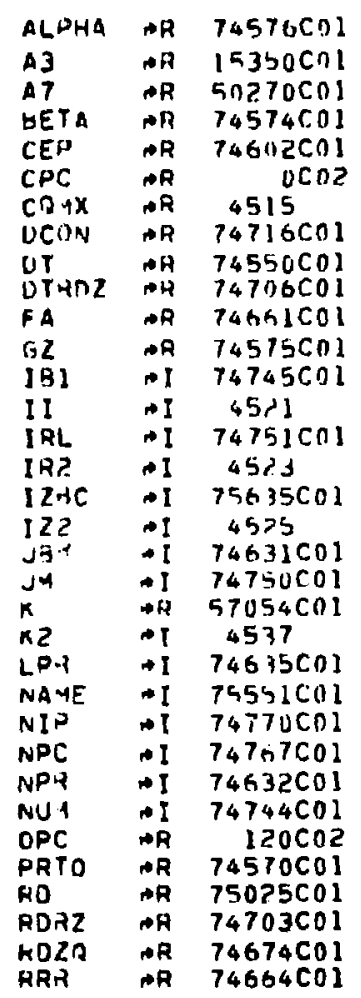

\section{name Locatiun}

\section{AI $\rightarrow H$ OCOI}

$A 4 \quad \rightarrow R \quad 24134 \mathrm{COI}$

$A B \quad \rightarrow H \quad 57054 \mathrm{COI}$

ATA OH $74577 C O$

CLK $\quad \mathrm{H} \quad 74724 \mathrm{COI}$

CHL HN 745F6COI

CI $\quad 7456360$

IICP $P$ TH TAKIUCOI

FC OI $74713 \mathrm{COI}$

I I 4517

ICNM $\rightarrow 14520$

[M I $7474 \mathrm{ACO}$

IHPC II 7556300I

If $I$ I $74764 \mathrm{COI}$

ILT I I $74754 \mathrm{CO}$ I

II II 4576

$\begin{array}{ll}\text { JHI } & \text { II } 74741 \mathrm{COI} \\ \text { JNM } & \text { I } 74763 \mathrm{COI}\end{array}$

$K K \quad I \quad 4534$

$K 3$ I 4540

LWR $\quad$ I $74636 \mathrm{CII}$

NCP + I $74766 C O 1$

NOC I $74773 \mathrm{CO}$

NOL II $74633 \mathrm{COI}$

NPFT $I 74760001$

NWR I $74634 \mathrm{CO}$

$P \quad O H \quad 41504 \mathrm{CO}$

RDR $\quad$ AR 4547

RIIT OR $74661 C 0$

$\begin{array}{lll}\text { AIDT } & A R & 74704 \mathrm{CO} \\ \text { RP } & \rightarrow R & 4553\end{array}$

PRHH $+R \quad 74665 \mathrm{CO}$

$\begin{array}{lcc}\text { STMT NO* LOCATION } \\ 3 & 545 \\ 230 & 30 \\ 360 & 200 \\ 470 & 366 \\ 600 & * & 514\end{array}$

STMT NOH LOCATION

450
250

$250 \rightarrow 45$

$400 * 210$

$500 \quad 401$
$750 \quad+\quad 515$

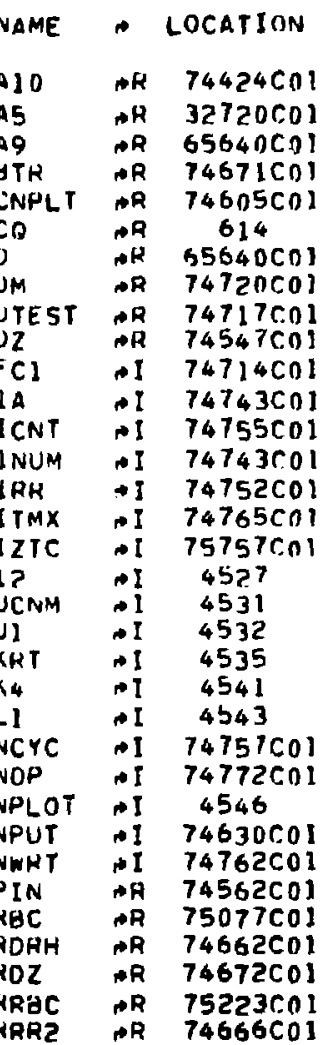

